\title{
Modelling Irrigation Water Management under Water Shortage and Salinity Conditions: 1- Evaluation of The Current Irrigation and Drainage Management Practices in South Kazakhstan
}

\author{
Abdulaziz, A. M. ${ }^{1}$, Saleh, M. ${ }^{1}$ and Robin Wardlaw ${ }^{2}$
}

\begin{abstract}
The WAVE model was modified to include the effect of salinity on crop transpiration, and used to simulate soil water balances, to investigate long-term salinity build-up in the root zone, and in conjunction with a crop yield response model to assess their effect on crop yield. The WAVE_MS model has been applied to evaluate current irrigation and drainage practices in South Kazakhstan. According to the results of simulation runs, cotton yield in the area would be reduced to a very low level within 25 years if irrigation and drainage practices are not changed. Inadequacy in water applications and increasing soil salinity are brining about this reduction. For the problem considered in this study, the WAVE_MS model, along with the crop yield response model, can be used as a tool for assessing the impact of different irrigation and drainage scenarios on crop yield. The results demonstrate that the modelling approach is robust and applicable under arid and semi-arid conditions and to a wide range of water shortage and salinity conditions.
\end{abstract}

Keywords: water management, salinity, mathematical modelling.

\section{INTRODUCTION}

Water stress and salinity are at present significant threats to sustainable irrigated agriculture in many parts of the world. With continued rapid population growth, and increasing dependence on irrigated agriculture to maintain food security, it is essential that improved approaches to irrigation and drainage management be found. The problems recently experienced in South Kazakhstan serve to highlight the issues. Cotton yields were reduced by about $40 \%$ due to water and salinity stress over period of about 10 years following deterioration of irrigation and drainage management systems. This in turn resulted in considerable decrease in net incomes from crop production (ADB, 1997; Mott MacDonald, 1999). Sustainable irrigation and drainage management to maintain and improve crop production is one of the most significant needs in areas under the effects of water stress and salinity. What is required in managing water and soil salinity is a means of assessing how different irrigation and drainage practices affect potential crop yield, and long term sustainability. For this reason, there is an urgent need to research robust and more efficient modelling approaches to improve assessment of crop yield associated with water and salinity stress.

Advances in computer technology in recent decades have permitted improvements in mathematical modelling of crop, soil and climate systems. Vadose zone models can provide useful information about the impact of different irrigation and drainage practices. Many models have been developed and used to simulate water and solute flux in the crop rootzone (Vanclooster, et al., 1994; Fernandez et al., 2002; Simunek, et al., 1996; Simunek, et al., 1999; Droogers et al., 2000; Wang et al., 2001; Zhang and Dawes, 1998; Van Dam et al., 1997; Van Dam, 2000; Smets et al., 1997; Joshi et al., 1995). These models can deal with the interaction between the soil and crop and water management variables such as irrigation, leaching and drainage. They can be used to determine the most beneficial combinations between water management variables leading to sustainable crop production. Vadose zone models are increasingly being used to evaluate alternative management practices and subsequently to identify the most efficient management strategies for different sets of conditions (Querner et al., 1997; Droogers and Kite, 2001; Droogers and Torabi, 2002; Kite and Droogers, 2000a; Qureshi et al., 2002).

A modified WAVE_MS model (Saleh, 2006) has been developed for modelling irrigation water management under water shortage and salinity conditions. The developed approach leads to a computational procedure that is able to deal with the combined effects of water and salinity stress on crop transpiration and on crop yield. This paper describes the application of the WAVE_MS model to the Makhtaaral Region of South Kazakhstan to evaluate the present irrigation and drainage practices.

\footnotetext{
${ }^{1}$ Alfateh University, Faculty of Agriculture, Soil and Water Department, PO Box 13019, Tripoli, Libya, e-mail: m_alazhari@yahoo.com

${ }^{2}$ Institute for Infrastructure and Environment, School of Engineering and Electronics, University of Edinburgh, AGB Building, King's Buildings, Mayfield Rd., Edinburgh, EH9 3JL

Received May 5, 2009, Accepted August 16, 2009
} 


\section{MATERIALS AND METHODS}

\section{The WAVE_MS model Set-up and Calibration}

The ability of any mathematical model to produce reliable output depends on the availability of reliable input data, as well as the accuracy of the model in representing the physical processes of the prototype. In most systems being modelled there are process representations that cannot be adequately parameterised by field measurement alone, perhaps because of high spatial variability. Because of this, most models require calibration. Calibration is the process through which model parameters are modified to enable the model to closely match the field observations (Gupta et al., 1998). In the WAVE_MS model, the parameters are those required by the van Genuchten equation (van Genuchten, 1980):- saturated and residual soil moisture content $\left(\theta_{s}\right.$ and $\left.\theta_{r}\right)$, the inverse of the air entry value $(\alpha)$, the shape parameters ( $n$ and $m$ ). The calibration of solute distribution constant $\left(K_{d}\right)$ is required for salinity model.

Field determination of these parameters is very difficult and values may vary widely between relatively close locations. Trial and error procedures can be used, however, to refine parameter values to those that yield optimum simulation of soil moisture and salinity. This is the calibration approach adopted here.

\section{Field Data Collection}

The University of Edinburgh has been involved with Mott MacDonald (consulting engineers) on the Water Resources Management and Land Improvement Project (WRMLIP) in South Kazakhstan. The project investigated water management practices, and much of the data collected has been available for and widely used in the research described in this paper.

Mott MacDonald (2003a) have presented field data collected at three pilot areas in the Makhtaaral region of South Kazakhstan. The programme commenced in October 2000. The objective of the data collection programme was to collect the data necessary to calibrate the mathematical models of the irrigation system being developed by the WRMLIP project. In particular the data were required for the WAVE_MS model.

The following data were collected during 2001 at each pilot area (Mott MacDonald, 2002):

- Daily meteorological data for the Lenina weather station, including rainfall, daily air temperature and relative humidity data.

- Physical soil characteristics (particle size distribution, bulk density, porosity, infiltration, field capacity, wilting point etc.). Soil characteristics have been observed at a number of locations in each of the pilot areas, with sampling at different depths from the surface to a depth of $3 \mathrm{~m}$.

- Time series of soil moisture characteristics with depth based on laboratory analysis of soil samples collected.

- Chemical composition of irrigation water, soils, groundwater and drainage water.

- Time series of groundwater levels.

- Leaching and irrigation water applications, timing and field distribution.

- Crop characteristics for cotton, including planting dates, development stages, rooting depths and yields.

- An evaluation of water and salt balances in the pilot areas during 2001.

The field data collection programme in 2001 provided infiltration characteristics at different depths as well as definition of permanent wilting point and saturated moisture content at different depths. These data were obtained by laboratory analysis of soil samples taken at $200 \mathrm{~mm}$ depth intervals from the three pilot areas, with 9 sampling locations in each pilot area. The WAVE_MS model was set-up for each location using the terminal infiltration rate and soil properties for the sampling point closest to that location as model input. There were no measurements of soil moisture tension data during the 2001 collection programme. The pilot areas were Birlik, Karaoi and Makhtali. The locations of the pilot areas are shown in Appendix 1 ((Mott MacDonald, 2003a).

In 2002, automatic soil monitoring equipment was installed in the pilot areas, providing continuous and discrete observations of soil moisture content, soil moisture tension and electrical conductivity measurements. Soil moisture was measured at a large number of sites in each pilot area using the Diviner probe, which is portable and permits a soil moisture profile to be observed. Soil moisture was also measured at three depths $(300,600$ and $1000 \mathrm{~mm})$ at the centre of each pilot area using the EnviroScan sensor. This equipment was fixed and permitted continuous measurements. A considerable number of dual measurements of soil moisture by Diviner probe and gravimetric laboratory analysis were carried out in each pilot area. However, the evaluation of the soil monitoring equipment results highlighted certain problems associated with the data obtained from both the soil monitoring equipment and from gravimetric soil moisture analysis. Significant variations were found between the data measured by each of the methods. The 2002 field data collection programme also provided soil 
electrical conductivity measurements using a Sigma Probe. A problem associated with this instrument was that, it was unable to produce reliable measurements of conductivity in the very dry soil samples for the top 200 $m m$ of soil.

\section{Meteorological Data}

The climate of South Kazakhstan is continental. The semi-arid steppes are characterised by extremely low rain, hot summers and cold winters. Climatic data were available from the Lenina weather station for the period 1990-2001. Lenina lies in the centre of the project area and is representative of the area (Mott MacDonald, 2000b). The WAVE_MS model requires daily rainfall and reference crop evapotranspiration data as primary input. Figure 1 presents a summary of mean monthly precipitation, temperature, relative humidity and potential evapotranspiration $\left(E T_{o}\right)$ at the Lenina meteorological station.

The coldest month is January in which the mean daily air temperature is about $-2.0^{\circ} \mathrm{C}$. The hottest month is July with an average of $27.9^{\circ} \mathrm{C}$. The annual rainfall averages $310 \mathrm{~mm}$ and this falls mainly in winter and spring. The highest relative humidity is recorded in January, February and December at $83 \%, 80 \%$ and $80 \%$ respectively. Lowest values of relative humidity of $45 \%$ and $46 \%$ occur in June and July respectively.

Mean monthly reference crop evapotranspiration, $E T_{o}$, was determined for Lenina by Mott MacDonald
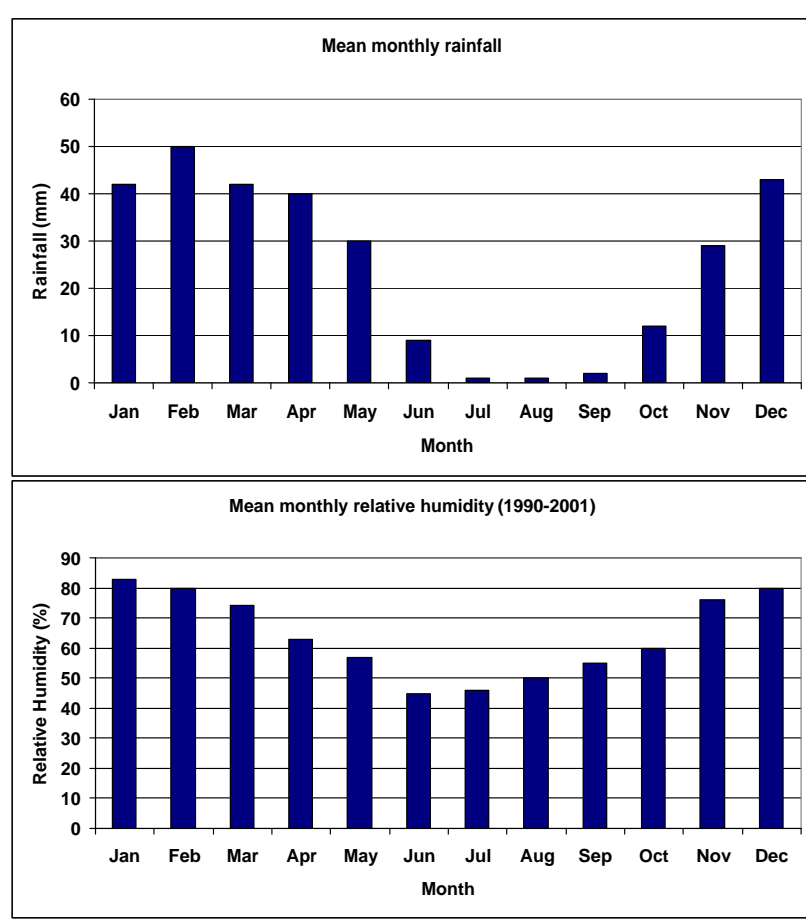

(2000b). Potential evapotranspiration reaches its highest value of $6.9 \mathrm{~mm} / \mathrm{day}$ in June. The lowest average evapotranspiration values of $0.67 \mathrm{~mm} / \mathrm{day}$ and 0.65 $\mathrm{mm} /$ day occur in January and December respectively.

\section{RESULTS AND DISCUSSIONS}

\section{Soil characteristics}

The WRMLIP field data collection programme provided both soil physical and chemical property data. The organic matter content in the project area was very low at $1.0 \%-1.5 \%$. According to the Kachinsky classification criteria (WUFMAS, 1999), the upper soil layers, mostly to 1-meter depth are classified as medium loam whereas light loam is the most common classification in the lower 2 meters of the soil profile. The average values of bulk density over all the soil layers are in the range from $1.42-1.67 \mathrm{~g} / \mathrm{cm}^{3}, 1.41$ $1.7 \mathrm{~g} / \mathrm{cm}^{3}$ and $1.41-1.56 \mathrm{~g} / \mathrm{cm}^{3}$ in the Makhtali, Birlik and Karaoi pilot areas respectively. Higher bulk density values were identified in the plough pan layer $20-40 \mathrm{~cm}$. The average porosity values ranged from $36.5 \%-46.2 \%, 37.5 \%-47.2 \%$ and $43.0 \%-47.2 \%$ in the Makhtali, Birlik and Karaoi pilot areas respectively. No significant variations in the soil porosity were identified between the three pilot areas. The soil of the study area can be considered as extremely porous in most depths.

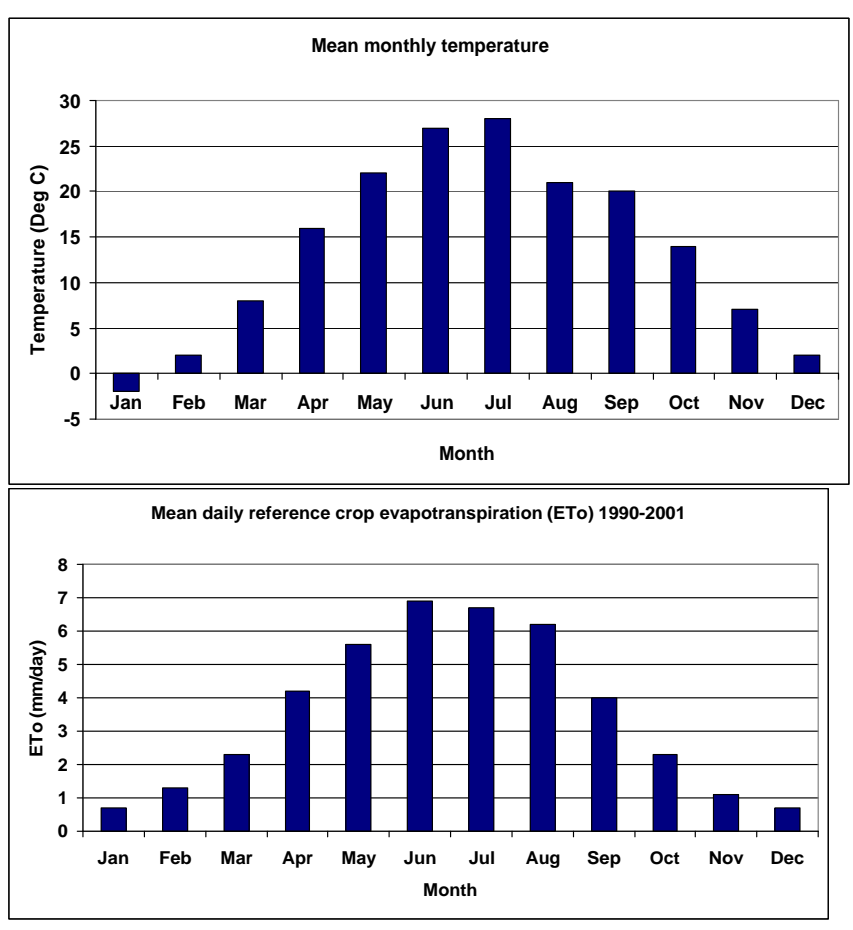

Figure 1. Climatic indicators at Lenina 
The WRMLIP data collection report provided soil salinity data at different depths for each pilot area in terms of total soluble salts (TSS) along with the ionic balances in $\%$ of salts by weight of dry soil. Local classification of salinity is based on the percentage of salts by weight in an aqueous extract of soil and on chloride concentration, whereas the International classification of salinity is based on the electrical conductivity $(E C)$ of a saturation extract of the soil (WUFMAS, 1999). There were no electrical conductivity measurements available in the years 2000 and 2001. However, a relationship was established between percentages of total soluble salts $(T S S)$ and electrical conductivity (EC) (Mott MacDonald, 2003b) on the basis of $E C$ measurements in 2003.

The average values of TSS for each layer were used as initial values for WAVE_MS. According to the local classification, soils in Makhtali and Birlik is classified as highly saline in the upper soil layers to moderately saline in the bottom layers below the rootzone. Soils are classified as non-saline in the Karaoi area. On the basis of the international classification system (WUFMAS, 1999), the majority of layers in Makhtali and Birlik tend to be classified as highly saline, and in Karaoi are classified as slightly saline instead of non-saline with the local classification. Soil salinity in Makhtali and Birlik is above the threshold value for damage to most crops based on the criteria described in the FAO Irrigation and Drainage Paper 56 (Allen et al, 1998). However, it is still below the threshold value in Karaoi.

\section{Table 2. Growth stages for cotton in pilot Areas}

\begin{tabular}{|c|c|c|c|c|c|}
\hline \multirow[t]{2}{*}{ Stage of growth } & \multirow[t]{2}{*}{ Kc } & \multicolumn{4}{|c|}{ Dates of Stage (and length in days) } \\
\hline & & Makhtali & Birlik & & Karaoi \\
\hline Planting & 0.4 & $17 / 4$ & $1 / 5$ & & $14 / 4$ \\
\hline End Initial stage & 0.4 & $19 / 5(32)$ & $31 / 5(30)$ & & $18 / 5$ \\
\hline End development & 1.15 & $29 / 6(41)$ & 10/7 (37) & & $27 / 6(40)$ \\
\hline End mid stage & 1.15 & $19 / 08(52)$ & $1 / 09(52)$ & & $17 / 08(50)$ \\
\hline End late stage & 0.6 & $15 / 10(56)$ & $15 / 10(45)$ & & $15 / 10(58)$ \\
\hline \multicolumn{6}{|c|}{ Table 3. Crop root development in each pilot Area } \\
\hline \multicolumn{2}{|c|}{ Makhtali } & \multicolumn{2}{|c|}{ Birlik } & \multicolumn{2}{|c|}{ Karaoi } \\
\hline Date & Depth (mm) & Date & Depth (mm) & Date & Depth (mm) \\
\hline $29 / 5$ & 400 & $9 / 6$ & 200 & $27 / 5$ & 600 \\
\hline $29 / 6$ & 600 & $10 / 7$ & 600 & $27 / 6$ & 1400 \\
\hline $21 / 7$ & 1400 & $3 / 8$ & 1000 & $15 / 7$ & 2200 \\
\hline $14 / 8$ & 2000 & $27 / 8$ & 1600 & $12 / 8$ & 2800 \\
\hline $15 / 10$ & 2400 & $15 / 10$ & 1800 & $15 / 10$ & 3000 \\
\hline
\end{tabular}

Soil salinity has significantly increased in the WRMLIP project area since 1990. There has been a significant increase in the area classified as moderately saline. The total area classified, as moderately saline in 1990 was 4495 hectare (21\% of the Phase I area) and 6123 hectare (29\% of the Phase II area) in the Phase I and Phase II areas respectively. Within a 9 year period, these areas had increased to be 9644 hectare (45\% of the Phase I area) and 10334 hectare (49\% of the Phase II area) in the same phases respectively (Mott MacDonald, 2004). The average rate of increase has been $2.4 \%$ and $2.0 \%$ per year respectively.

\section{Crop Characteristics} coefficients $\left(K_{C}\right)$, rooting depths and leaf area index ( $L A I)$ at various stages of growth are needed to run the WAVE model. Data on cotton stages of growth were collected during the 2001 field data collection programme. The length of cotton growth stages and the values of $K_{C}$ used during the modelling are presented in Table 2.

The data collection report (Mott MacDonald, 2003a) also provides root depth and distribution data in each of the pilot areas, measured during 2001. These data were used as input in the WAVE_MS model. These data are presented in Table 3 .

Leaf area indices are used in the WAVE model to partition evapotranspiration into evaporation and transpiration. The leaf areas used in modelling are presented in Table 4.
The crop characteristics such as crop 
Table 4. Leaf area indices used in WAVE Modelling

\begin{tabular}{cc}
\hline Days from planting & Leaf area \\
\hline 6 & 0 \\
7 & 2.35 \\
37 & 5.60 \\
150 & 6.40 \\
181 & 0.0 \\
\hline
\end{tabular}

\section{Recent Irrigation Practices}

Leaching water depths, dates of application and salinities in 2001 are presented in Table 5. Tables 6 and 7 show depths, dates and salinities of the irrigation water application. In 2001, irrigation water was applied only twice during the growth period between mid April and October. However, water was applied only once at Makhtali location P15, and at Birlik P3 and P12. Water application in Makhtali and Birlik was not uniform in either leaching or irrigation and varied across the pilot areas.

\section{WAVE Model Parameterisation}

\section{Water Transport Parameters}

The water transport module requires soil moisture retention and hydraulic conductivity parameters to be specified for each soil layer. These parameters are required by the van Genuchten (1980) equation. The WAVE_MS model was set-up initially with soil hydraulic parameters derived from the field observations of soil moisture content and soil moisture tension.

Table 8 presents the critical pressure head values used to model the effect of water stress on crop transpiration according to the function proposed by Feddes et al., (1978). These values were based on the values recommended in the WAVE reference manual (Vanclooster et al., 1994).

Crop coefficients and leaf area indices values used for the WAVE_MS modelling are presented in Tables 2 and 4.

Table 5. Leaching applications at modelled locations within the project area, 2001

\begin{tabular}{|c|c|c|c|}
\hline Location & Dates & $\begin{array}{l}\text { Leaching } \\
\text { Depth (mm) }\end{array}$ & $\begin{array}{l}\text { Water Salinity } \\
(\mathrm{g} / \mathrm{l})\end{array}$ \\
\hline Makhtali, location P3 & $11 \mathrm{Mar}$ - $13 \mathrm{Mar}$ & 60 & 0.8 \\
\hline Makhtali, location P9 & $11 \mathrm{Mar}-13 \mathrm{Mar}$ & 60 & 0.8 \\
\hline Makhtali, location P15 & $6 \mathrm{Mar}-7 \mathrm{Mar}$ & 147 & 0.8 \\
\hline Birlik, location P3 & $26 \mathrm{Jan}-2 \mathrm{Feb}$ & 184 & 0.8 \\
\hline Birlik, location P12 & $8 \mathrm{Mar}-11 \mathrm{Mar}$ & 251 & 0.8 \\
\hline Karaoi, location P3 & $9 \mathrm{Mar}-15 \mathrm{Mar}$ & 156 & 0.792 \\
\hline Karaoi, location P6 & $9 \mathrm{Mar}-15 \mathrm{Mar}$ & 156 & 0.792 \\
\hline \multicolumn{4}{|c|}{ Table 6. First Irrigation applications at modelled locations within the project area, 2001} \\
\hline Location & Dates & $\begin{array}{c}\text { Irrigation } \\
\text { Depth (mm) }\end{array}$ & $\begin{array}{l}\text { Water Salinity } \\
(\mathrm{g} / \mathrm{l})\end{array}$ \\
\hline Makhtali, location P3 & $4 \mathrm{Jul}-5 \mathrm{Jul}$ & 65 & 1.436 \\
\hline Makhtali, location P9 & $4 \mathrm{Jul}-5 \mathrm{Jul}$ & 65 & 1.436 \\
\hline Makhtali, location P15 & 24 Jun -25 Jun & 86 & 1.436 \\
\hline Birlik, location P3 & 1 Aug -2 Aug & 33 & 1.2 \\
\hline Birlik, location P12 & 2 Aug - 3 Aug & 65 & 1.2 \\
\hline Karaoi, location P3 & 28 May - 5 Jun & 92 & 1.046 \\
\hline Karaoi, location P6 & 28 May - 5 Jun & 92 & 1.046 \\
\hline \multicolumn{4}{|c|}{ Table 7. Second Irrigation applications at modelled locations within the project area, 2001} \\
\hline Location & Dates & $\begin{array}{c}\text { Irrigation } \\
\text { Depth (mm) }\end{array}$ & $\begin{array}{l}\text { Water Salinity } \\
(\mathrm{g} / \mathrm{l})\end{array}$ \\
\hline Makhtali, location P3 & 18 Aug - 20 Aug & 70 & 1.214 \\
\hline Makhtali, location P9 & 8 Aug -20 Aug & 70 & 1.214 \\
\hline Makhtali, location P15 & - & - & - \\
\hline Birlik, location P3 & - & - & - \\
\hline Birlik, location P12 & - & - & - \\
\hline Karaoi, location P3 & $15 \mathrm{Jul}-18 \mathrm{Jul}$ & 43 & 1.128 \\
\hline Karaoi, location P6 & $15 \mathrm{Jul}-18 \mathrm{Jul}$ & 43 & 1.128 \\
\hline
\end{tabular}


Table 8. Critical pressure head values used in WAVE modelling

\begin{tabular}{clc}
\hline Parameter & \multicolumn{1}{c}{ Description } & Value \\
\hline$h_{0}$ & The pressure head below which the plant roots start to extract water from the soil & -10 \\
$h_{1}$ & The pressure head below which the roots start to extract water optimally from the soil & -46 \\
$h_{2}$ & The pressure head below which the roots can no longer extract water optimally & -500 \\
$h_{2}$ & The pressure dead at which the water uptake by plant roots ceases & -16000 \\
\hline
\end{tabular}

The top boundary condition is determined by the allowable minimum pressure head at the soil surface and the maximum ponding depth. A maximum ponding depth of $10 \mathrm{~mm}$ has been used. When the maximum is reached, the excess water runs off. The lower boundary condition was specified by the observed groundwater level, for calibration purposes.

\section{Solute Transport Parameters}

There are several parameters that need to be specified for use in the solute transport module. Table 9 lists the model parameters used along with the values adopted.

The $a_{k}, b_{k}$ and $f$ values are based on the values recommended in the WAVE reference manual (Vanclooster et al., 1994). Most other values are based on field data. $f$, and $\alpha$ are required when the mobile/immobile concept is considered.

\section{C_YIELD Parameters}

The yield response to water and salinity functions in the C_YIELD programme require the following data in addition to the data collected and used in the WAVE_MS model:

- Crop yield response factors required by Rao function (Rao et al., 1988) to model crop yield response to water. In this research the C_YIELD model was set-up using crop yield response factors for each stage of growth published in Doorenbos and Kassam (1979). The values used for cotton were $0.20,0.5,0.45$ and 0.25 for vegetative, flowering, yield formation and ripening growth stages respectively.

- Soil salinity threshold value, which is required to model yield response to salinity. For cotton, the value of the threshold salinity adopted was 7.7 $d S / m$, (Allen et al., 1998).

- The rate, at which relative crop yield declines with increasing salinity, which is also required for

Table 9. Solute transport parameters used in WAVE modelling

\begin{tabular}{clc}
\hline $\begin{array}{c}\text { Paramete } \\
\mathbf{r}\end{array}$ & \multicolumn{1}{c}{ Description } & Value \\
\hline Dif & Chemical diffusion coefficient of the considered solute in pure water $\left(\mathrm{mm}^{2} d a y^{-1}\right)$ & 0.01 \\
$a_{k}$ & Empirical constant used in the calculation of the effective diffusion coefficient & 0.075 \\
$b_{k}$ & Empirical constant used in the calculation of the effective diffusion coefficient & 10 \\
$f$ & Fraction of the adsorption sites situated in contact with the region & 1 \\
\hline
\end{tabular}

salinity modelling. The model was set-up with value of 5.2 (Allen et al., 1998).

\section{WAVE_MS Model Calibration}

The WAVE_MS model was set-up and calibrated using the field data from October 2000 to October 2002. Calibration was based on simulation of soil moisture content, and soil moisture tension (which was available for 2002 only), and soil salinity.

\section{Methods of Establishing Simulation Quality}

To assess the simulation quality and subsequently the calibrated model performance, some statistical tests (Loague and Green, 1991; Vazquez and Feyen, 2003; Xevi et al., 1996; Legates and McCabe, 1999) were used. The statistical measures used in evaluating simulation quality, are Mean Absolute Error $(M A E)$, Relative Root Mean Square Error (RRMSE), Coefficient of Efficiency $\left(E F_{2}\right)$, Coefficient of Determination $(C D)$, Coefficient of Residual Mass $(C R M)$ and Pearson type Goodness of fit index $\left(R^{2}\right)$.

\section{Fitting Soil Moisture Retention Curves}

Soil moisture content and soil moisture tension relationships in the form of soil moisture retention curves, were developed at each of the pilot sites from the observed field data. These curves were conditioned by observed data of soil moisture tension and volumetric soil moisture contents at saturation and at wilting point at different depths at each pilot area. These data are summarised in Table 10 below. The objective has been to develop soil moisture retention curves that match the observed soil moisture data and reflect the field situation at each site. Soil moisture retention curves were fitted 


\begin{tabular}{clc}
\hline$K_{d}$ & Distribution coefficient (Litres $\left.\mathrm{Kg}^{-1}\right)$ & 5 \\
$\lambda$ & The soil solute dispersivity $(\mathrm{mm})$ & 77 \\
$\alpha$ & Empirical transfer coefficient $\left(\right.$ day $\left.^{-1}\right)$ & 0.01 \\
\hline
\end{tabular}

through a trial and error process of adjusting the $\alpha, n$, and $m$ parameters of the van Genuchten equation.

The soil moisture content and soil moisture tension data recorded at different depths for each of the pilot areas are plotted in Figure 2 along with the fitted retention curves. The parameters for the fitted retention curves are given in Table 11. These parameter values were used as initial values in the WAVE_MS model calibration.

It is clear from Figure 3 that the quality of much of the soil moisture and soil moisture tension data is poor, and that it lacks consistency. The observed data should
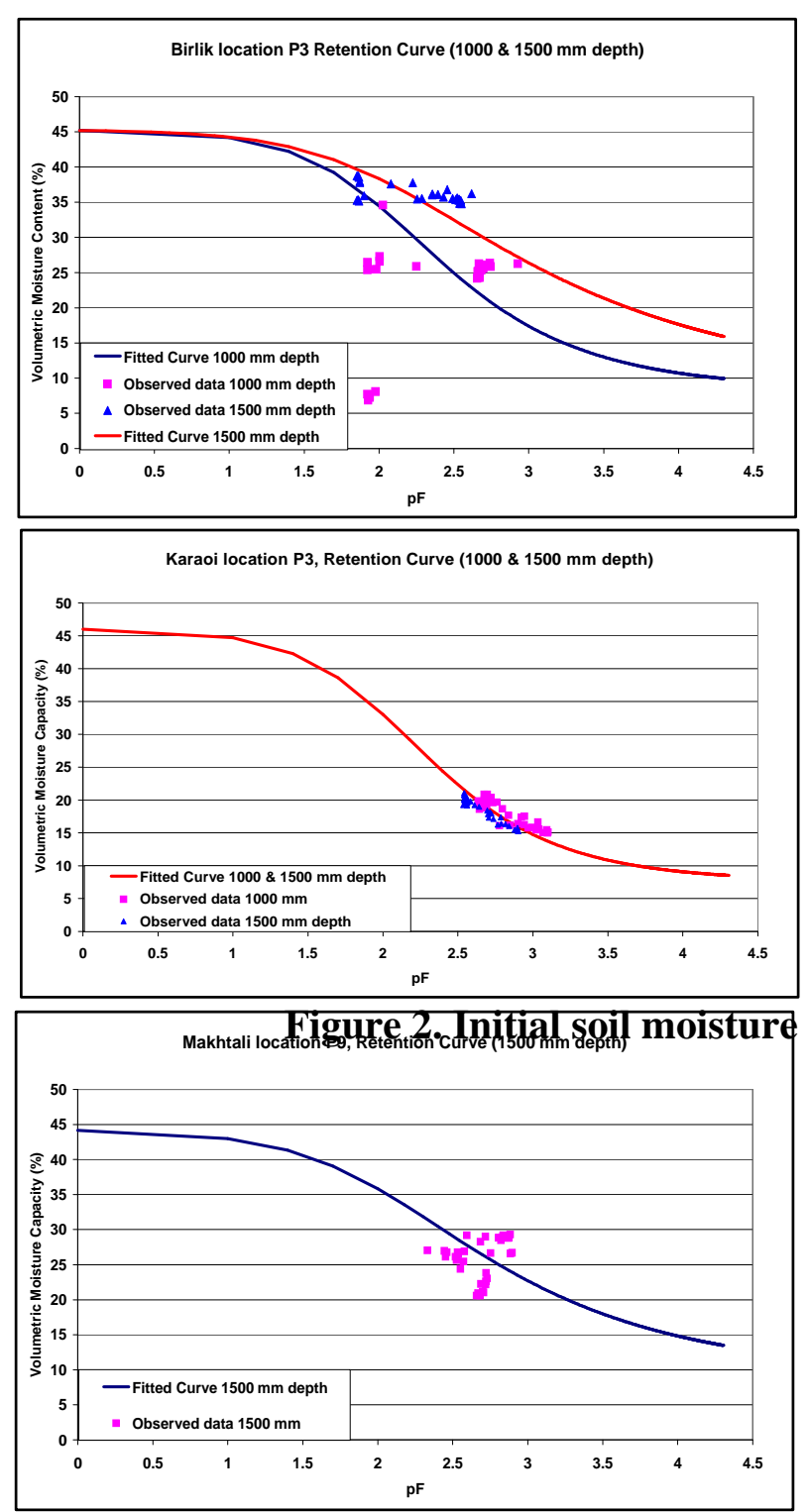

lie on a well defined relationship, but generally do not. The data are also available only for a relatively narrow range, with no data close to either saturation or wilting points. It is understood that equipment was late in arriving on site, and that this led to difficulties in calibrating equipment and resulted in very low and very high soil moisture contents being missed. The fitted soil moisture retention curves were adapted to pass through the available data at each site as well as possible. There are problems in the observed soil moisture tension data at many depths as there is a wide scatter between observed soil moisture tension data at the same moisture content.
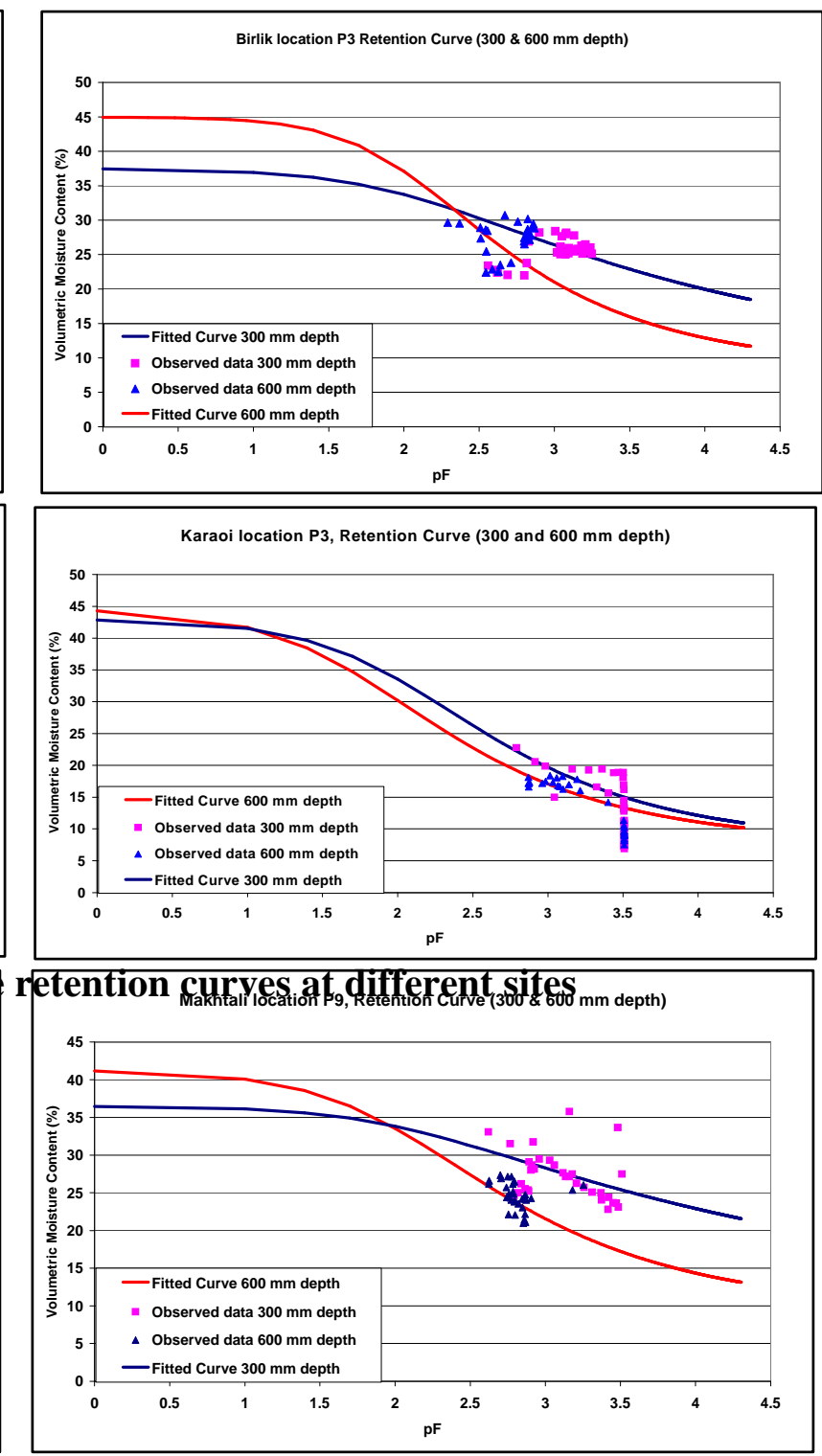
Table 10. Saturation $\theta_{s}$ and residual soil moisture contents $\theta_{r}$ at different soil depths

\begin{tabular}{lcccccc}
\hline Soil depth (cm) & \multicolumn{2}{c}{ Makhtali } & \multicolumn{3}{c}{ Birlik } & \multicolumn{2}{c}{ Karaoi } \\
\cline { 2 - 6 } & $\theta_{s}$ & $\theta_{r}$ & $\theta_{s}$ & $\theta_{r}$ & $\theta_{s}$ & $\theta_{r}$ \\
\hline $0-20$ & 46.2 & 9.3 & 47.2 & 8.4 & 46.5 & 7.7 \\
$21-40$ & 36.5 & 9.3 & 37.5 & 8.4 & 43.0 & 7.7 \\
$41-60$ & 41.3 & 9.3 & 45.0 & 8.4 & 44.6 & 7.7 \\
$61-80$ & 42.9 & 9.3 & 46.7 & 8.4 & 47.2 & 7.7 \\
$81-100$ & 44.4 & 9.3 & 46.8 & 8.4 & 47.2 & 7.7 \\
$101-150$ & 44.6 & 9.3 & 46.6 & 8.4 & 46.8 & 7.7 \\
$151-200$ & 44.8 & 9.3 & 45.0 & 8.4 & 45.5 & 7.7 \\
$201-250$ & 45.0 & 9.3 & 43.6 & 8.4 & 44.7 & 7.7 \\
$251-300$ & 44.1 & 9.3 & 43.3 & 8.4 & 44.9 & 7.7 \\
\hline
\end{tabular}

Table 11. Fitted soil moisture retention curve parameters at different soil depths

\begin{tabular}{lcccc}
\hline Pilot Area & Depth, mm & \multicolumn{2}{c}{ Parameter } \\
\cline { 2 - 4 } & 300 & $\boldsymbol{\alpha}$ & $\mathbf{n}$ & $\mathbf{M}$ \\
\hline \multirow{2}{*}{ Makhtali, location P9 } & 600 & 0.01 & 1 & 0.15 \\
& 1500 & 0.01 & 1 & 0.4 \\
\hline \multirow{2}{*}{ Birlik, location P3 } & 300 & 0.01 & 1 & 0.4 \\
& 600 & 0.01 & 1 & 0.2 \\
& 1000 & 0.01 & 1.3 & 0.35 \\
Karaoi, location P6 & 1500 & 0.01 & 1.2 & 0.3 \\
& 300 & 0.01 & 1 & 0.5 \\
& 600 & 0.02 & 1 & 0.5 \\
\end{tabular}

\section{Soil Moisture Content Calibration}

Following preliminary fitting of the soil moisture retention curve characteristics to the observed data, calibration of these parameters was carried out with WAVE_MS through matching observed and simulated soil moisture content. Using the parameter values presented in Table 11. large differences were found between observed and simulated soil moisture content at some depths especially in the top soil layers where simulated soil moisture content was often higher than observed. However, simulated soil moisture contents fit well with those observed at many depths at the locations under consideration, and only small differences were found at some other depths with patterns of changing soil moisture being reasonably simulated.

There are some issues related to data quality. For example, in early March following leaching, soil moisture content should be close to saturation. At Makhtali and Karaoi observed soil moisture content in this period was around 30\% at Makhtali and 25\% and Karaoi. The problem is thought most likely to be associated with sampling errors, particularly during 2002 data collection programme. In 2002 soil moisture was measured using automatic soil monitoring equipment and gravimetric laboratory analysis at a large number of sites in each pilot area. However, problems associated with the data obtained from both the soil monitoring equipment and from gravimetric soil moisture analysis were reported in the evaluation of the soil monitoring equipment results (Mott MacDonald, 2003b). Sample sizes for gravimetric measurements were smaller than standard, and calibration of some of the automatic equipment may have been based on incorrect gravimetric data.

Recognising that there have potentially been errors in soil moisture content measurement, and the soil moisture tension measurements used to derive the moisture retention curves, the soil moisture retention parameters were adjusted to improve the WAVE_MS model performance in simulating soil moisture. A series of model runs was carried out for the two years of observed soil moisture content data. In these runs the values of parameters used in the soil moisture retention and hydraulic conductivity equations $\left(\theta_{s}, \theta_{r}, \alpha, m\right.$, and $\left.n\right)$ were modified in a trial and error process to determine values that permitted reasonable simulation of the observed soil moisture data. In these runs observed groundwater levels were used as the lower boundary condition for the model. 
By modifying the soil moisture retention parameters described above, the simulated soil moisture content could match quite well with that observed in the four soil layers examined at most sites in the project area. Figure 3 is typical examples and show good agreement between observed and simulated soil moisture for the two years of observations available.

Generally, the modified WAVE model has satisfactorily simulated soil moisture content at all locations under consideration. The statistical indices show a reasonable model performance in predicting soil moisture content. $R^{2}$ ranged between 0.36 and 0.75 in most depths within the areas under consideration. In the calibration of soil moisture content using ECOMAG model which describes the processes of soil infiltration, evapotranspiration, soil water content, surface and subsurface flow and groundwater flow, Motovilov et al. (1999) considered that simulation results are considered to be good for values of $R^{2} \geq 0.75$, and satisfactory for $R^{2}$ between 0.36 and 0.75 . In addition, the values of the coefficient of efficiency $E F_{2}$ and the coefficient of determination $C D$, ranged between -0.08 and 0.66 ;
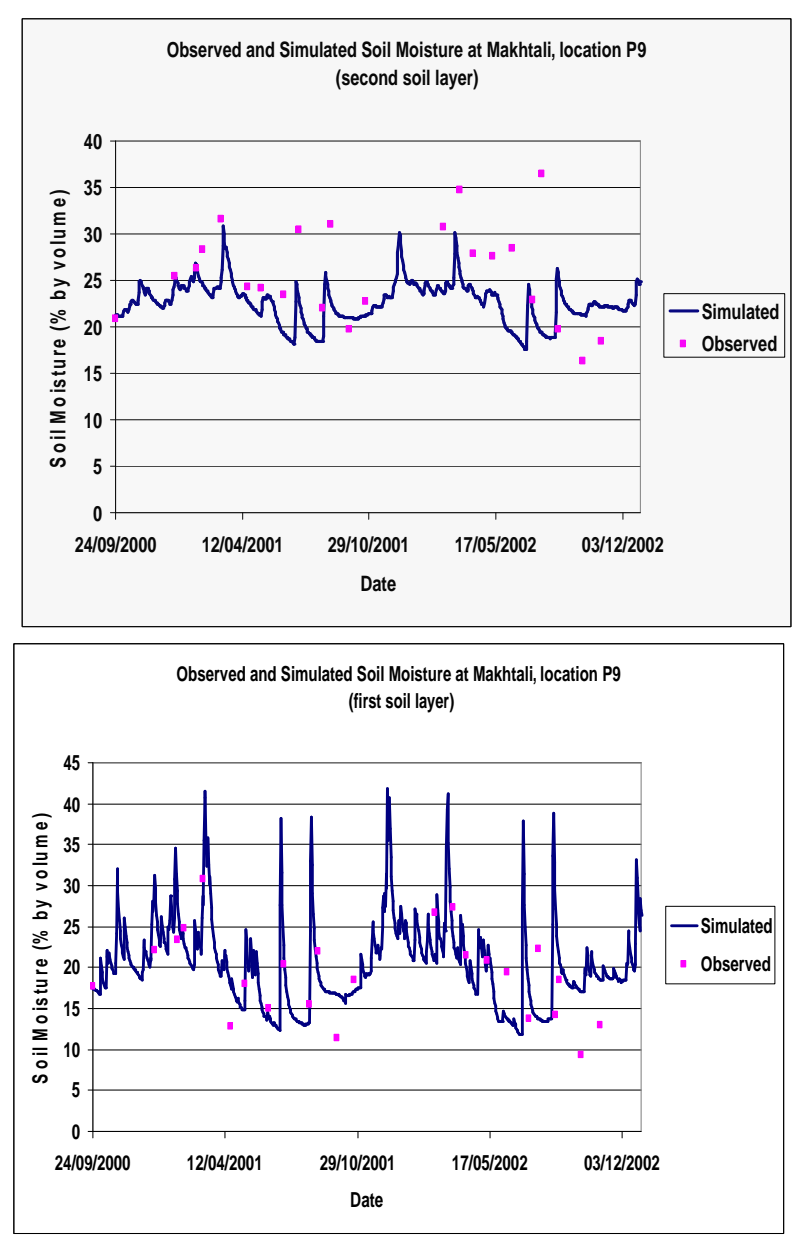

0.12 and 0.98 respectively which are reasonably close the optimum value of 1.0 at most sites. The coefficient of residual mass CRM show that the model predicted soil moisture content with minimum overestimation or underestimation in most sites.

The calibrated values of the soil moisture retention parameters for each of the sites modelled are summarised in Table 12. The calibrated soil moisture retention parameters $\left(\theta_{s}, \theta_{r}, \alpha, m\right.$, and $\left.n\right)$, result in re-defined soil moisture retention curves. These are shown in Figure 4. With the exception of the surface layers at Makhtali, the curves still represent the data reasonably well. It is known that a high water table at Birlik certainly caused problems with some of the automatic equipment in 2002, but the reason for the large discrepancy in the $300 \mathrm{~mm}$ and $600 \mathrm{~mm}$ depth layers at Makhtali are not clear. There are clearly discrepancies between the soil moisture content and soil moisture tension data at this site.
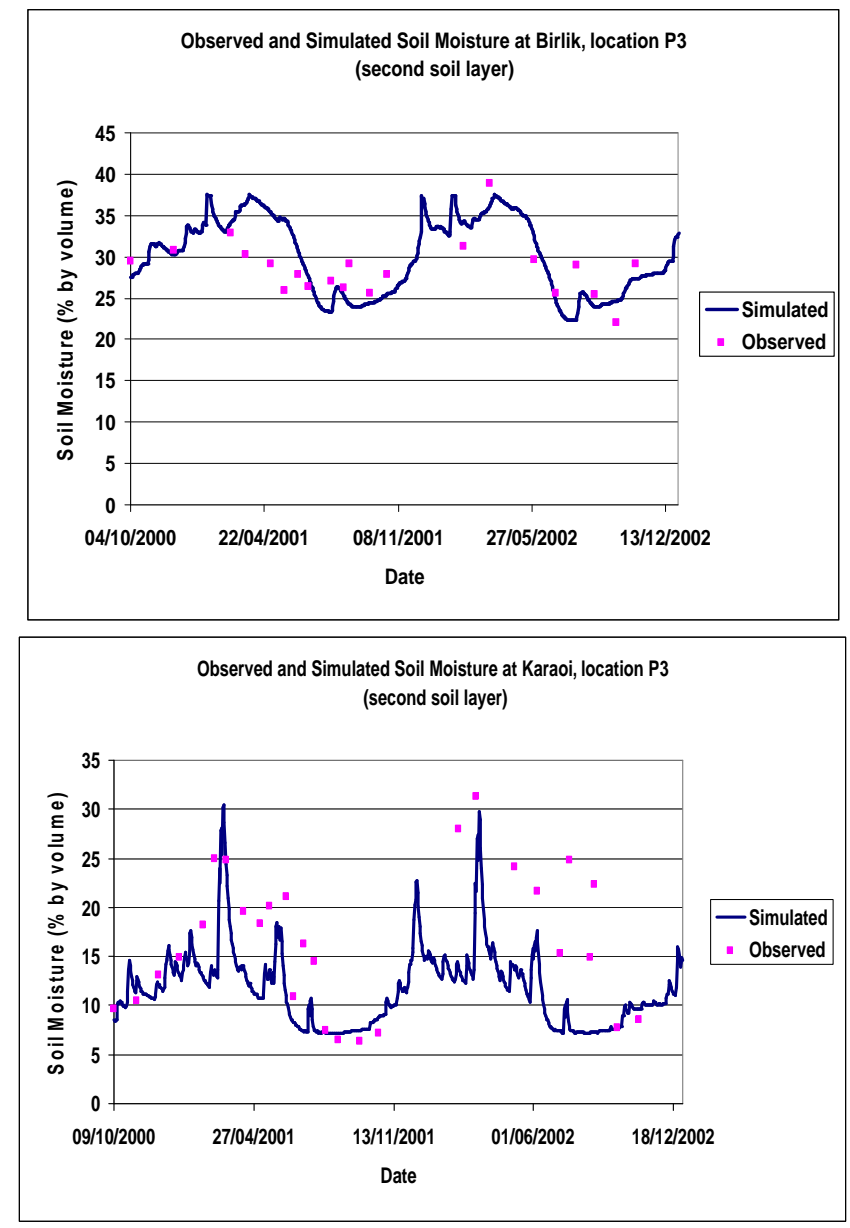


\section{different sites}

Table 12. Final Calibration Parameters

\begin{tabular}{|c|c|c|c|c|c|c|c|c|}
\hline \multirow[t]{2}{*}{ Pilot Area } & \multirow[t]{2}{*}{ Location } & \multirow[t]{2}{*}{ Layer } & \multirow[t]{2}{*}{ Depth } & \multicolumn{5}{|c|}{ MRC Parameters } \\
\hline & & & & $\theta_{r}$ & $\theta_{s}$ & $\alpha$ & $\mathbf{n}$ & $\mathbf{m}$ \\
\hline \multirow[t]{4}{*}{ Makhtali } & P3 & 1 & $0-200$ & 9 & 46 & 0.03 & 1.5 & 0.4 \\
\hline & & 2 & $200-400$ & 9 & 37 & 0.02 & 1.3 & 0.3 \\
\hline & & 3 & $400-600$ & 9 & 41 & 0.02 & 1.2 & 0.4 \\
\hline & & 4 & $600-8000$ & 9 & 44 & 0.01 & 0.8 & 0.3 \\
\hline \multirow[t]{4}{*}{ Makhtali } & P9 & 1 & $0-200$ & 9 & 46 & 0.03 & 1.4 & 0.4 \\
\hline & & 2 & $200-400$ & 9 & 37 & 0.02 & 1.3 & 0.3 \\
\hline & & 3 & $400-600$ & 9 & 41 & 0.02 & 1.2 & 0.4 \\
\hline & & 4 & $600-8000$ & 9 & 44 & 0.01 & 1.0 & 0.35 \\
\hline \multirow[t]{4}{*}{ Makhtali } & P15 & 1 & $0-200$ & 9 & 44 & 0.03 & 1.3 & 0.4 \\
\hline & & 2 & $200-400$ & 9 & 46 & 0.03 & 1.4 & 0.3 \\
\hline & & 3 & $400-600$ & 9 & 37 & 0.03 & 1.4 & 0.4 \\
\hline & & 4 & $600-8000$ & 9 & 41 & 0.01 & 0.8 & 0.3 \\
\hline \multirow[t]{4}{*}{ Karaoi } & P3 & 1 & $0-200$ & 7 & 44 & 0.05 & 1.6 & 0.6 \\
\hline & & 2 & $200-400$ & 7 & 43 & 0.04 & 1.5 & 0.5 \\
\hline & & 3 & $400-600$ & 7 & 45 & 0.05 & 1.4 & 0.5 \\
\hline & & 4 & $600-8000$ & 7 & 46 & 0.01 & 1.1 & 0.4 \\
\hline \multirow[t]{4}{*}{ Karaoi } & P6 & 1 & $0-200$ & 7 & 47 & 0.06 & 1.6 & 0.5 \\
\hline & & 2 & $200-400$ & 7 & 43 & 0.04 & 1.5 & 0.5 \\
\hline & & 3 & $400-600$ & 7 & 45 & 0.05 & 1.4 & 0.5 \\
\hline & & 4 & $600-8000$ & 7 & 46 & 0.01 & 1.1 & 0.4 \\
\hline \multirow[t]{4}{*}{ Birlik } & P3 & 1 & $0-200$ & 8 & 47 & 0.01 & 1.0 & 0.4 \\
\hline & & 2 & $200-400$ & 8 & 38 & 0.004 & 1.0 & 0.4 \\
\hline & & 3 & $400-600$ & 8 & 45 & 0.01 & 1.0 & 0.4 \\
\hline & & 4 & $600-8000$ & 8 & 45 & 0.004 & 1.0 & 0.4 \\
\hline \multirow[t]{4}{*}{ Birlik } & P12 & 1 & $0-200$ & 8 & 47 & 0.02 & 1.2 & 0.4 \\
\hline & & 2 & $200-400$ & 8 & 38 & 0.01 & 0.8 & 0.4 \\
\hline & & 3 & $400-600$ & 8 & 45 & 0.02 & 1.2 & 0.4 \\
\hline & & 4 & $600-8000$ & 8 & 45 & 0.01 & 0.7 & 0.4 \\
\hline
\end{tabular}

\section{Soil Moisture Tension}

Following soil moisture calibration, simulated soil moisture tension was compared with observed soil tension data where it was possible to do so. Time series of soil moisture tension data are available at different depths at Makhtali location P9, and at Karaoi location P3. The observed soil moisture tension data collected from the central site of Birlik were used in the calibration of Birlik location P3 at which there were no observed data available. Figure 5 shows the soil moisture retention curves at different sites and depths.

At Birlik, for all depths, there is reasonable agreement between observed and simulated soil moisture tension in terms of magnitude, and the results are as good as could be expected in the light of the moisture retention curves given. The effect of wetting and drying due to water application and root water uptake was not clear even in the top layer. In other words, the observed soil moisture tension data were less sensitive to irrigation application as compared with the simulated soil moisture tension. It is unfortunate that no data were available for the leaching period. No reliable tension data were available for the Birlik pilot site at locations P3 and P12. Moreover, according to the Working Paper No. 30 (Mott MacDonald, 2004), the monitoring equipment were not working efficiently particularly in Birlik due to poor drainage and water logging.

In Karaoi, the water table is lower than at Makhtali and Birlik, and this is clearly reflected in the relatively higher soil moisture tensions observed in the lower soil layers. The impact of two water applications on the soil moisture tension data is apparent in the upper soil layer. Perhaps the observed soil moisture tension data in this pilot area are more reliable than in other areas. The simulated data fitted the observed reasonably well. The simulated soil moisture tension matches well with the observed in the three depths under consideration, and especially in the bottom layer at a depth of $1500 \mathrm{~mm}$.

In Makhtali, location P9, there has been clear influence of the second irrigation application on the observed soil moisture tension data in the upper soil 
layer. However, it is apparent that the first irrigation was not effective, possibly because of the amount applied was too small. The results show an under prediction of the observed soil tension values at 300 mm depth.

However, the simulated soil moisture tension matches well with the observed in the other depths, especially in the bottom layer at $1500 \mathrm{~mm}$ depth. The under prediction of the observed soil moisture tension

data at $300 \mathrm{~mm}$ depth could be related to the chosen parameters in the soil moisture content calibration, but in view of the data problems that were known to exist, a further iteration of calibration was not carried out.

\section{Soil Salinity}

The soil salinity calibration was divided into two stages, in the first stage, a series of model sensitivity runs were carried out for the period 2001-2025. In these runs the sensitivity of salinity build up over the simulation period to the solute distribution constant $\left(K_{d}\right)$ was tested. This parameter is required in the mobile/immobile concept. In the second stage, soil salinity calibration was carried out by running the model for two years using observed soil salinity data at different depths from the pilot areas under
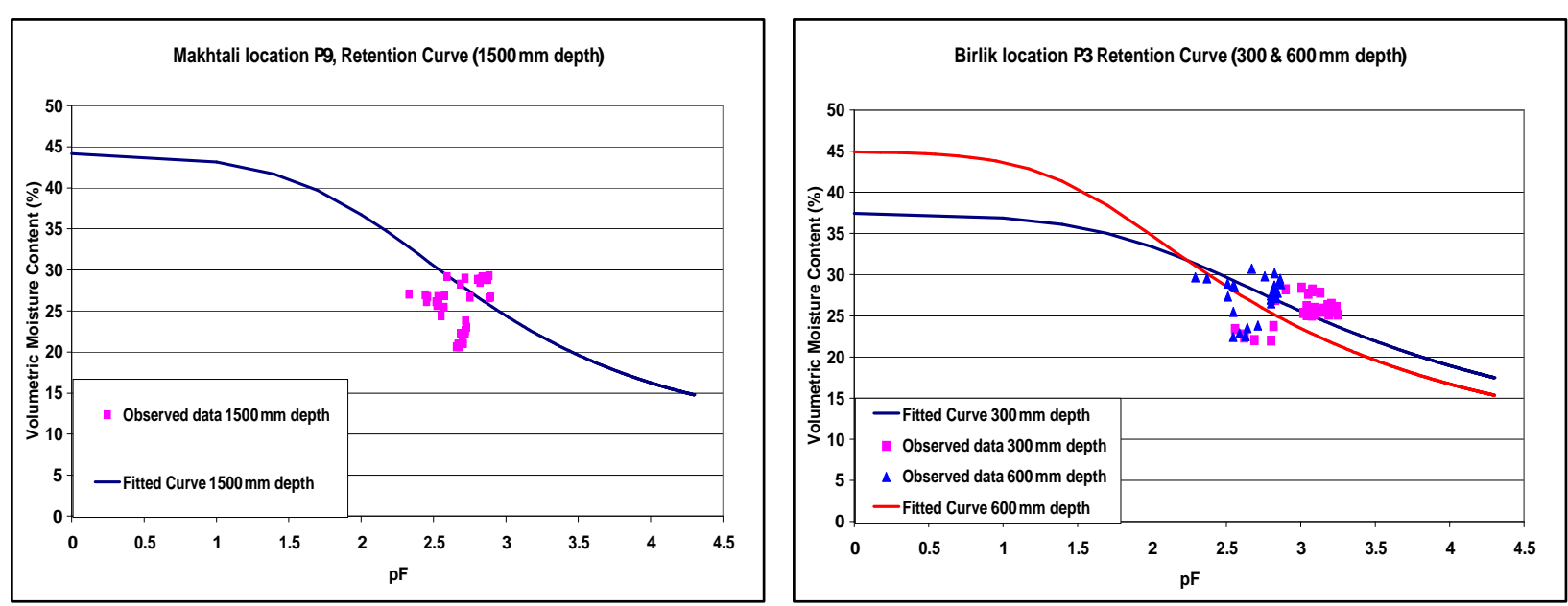

Figure 4. Fitted soil moisture retention curves at different sites

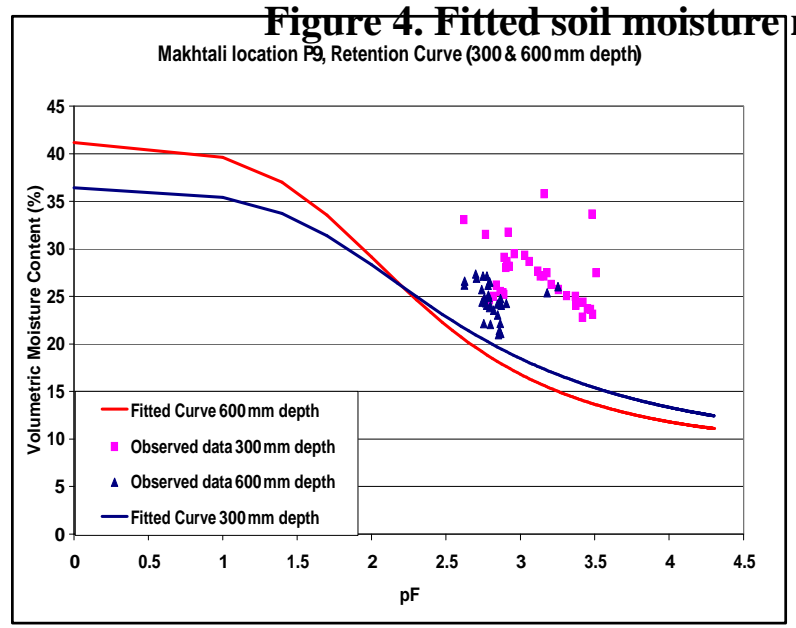

consideration. The objective was to match simulated and observed soil salinity by changing the distribution coefficient $K_{d}$ using a trial and error process.

The sensitivity of the solute distribution constant $\left(K_{d}\right)$ was tested for values of $0.5,1.0,2.0,3.0$, and 5.0. Figure 6 shows the influence of $K_{d}$ on salinity build up, assuming Karaoi soil characteristics. This parameter has a great effect on salinity build up by controlling the mass of solutes adsorbed on the soil complex. The higher the value of $K_{d}$, the greater the mass of solutes adsorbed on the soil particles in the top three layers. As a result the simulated leaching would be less effective than with lower values of $K_{d}$. In the bottom layer (600-8000 $\mathrm{mm}$ depth), there was slight increase in soil salinity with increasing the $K_{d}$ value due to the continuous accumulation of salts in this layer from the water table.

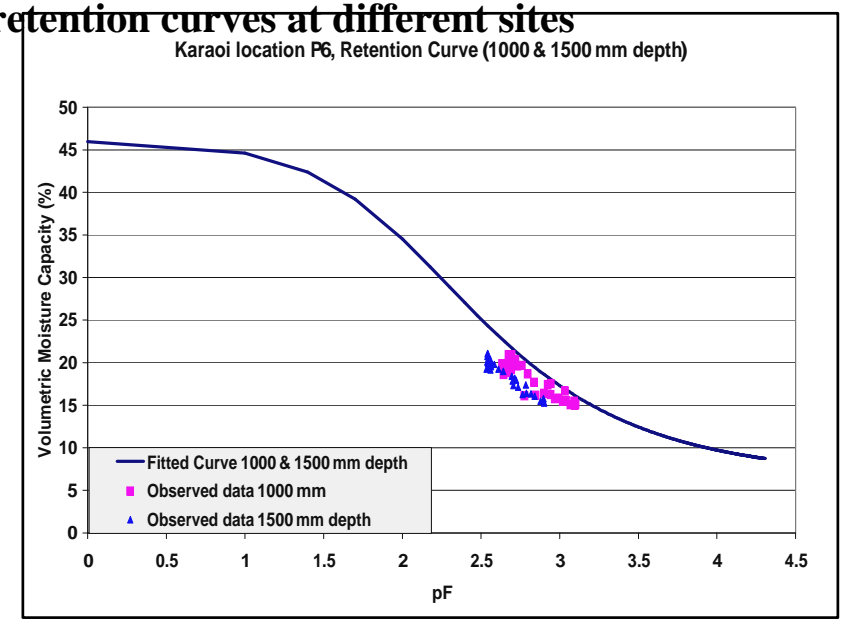



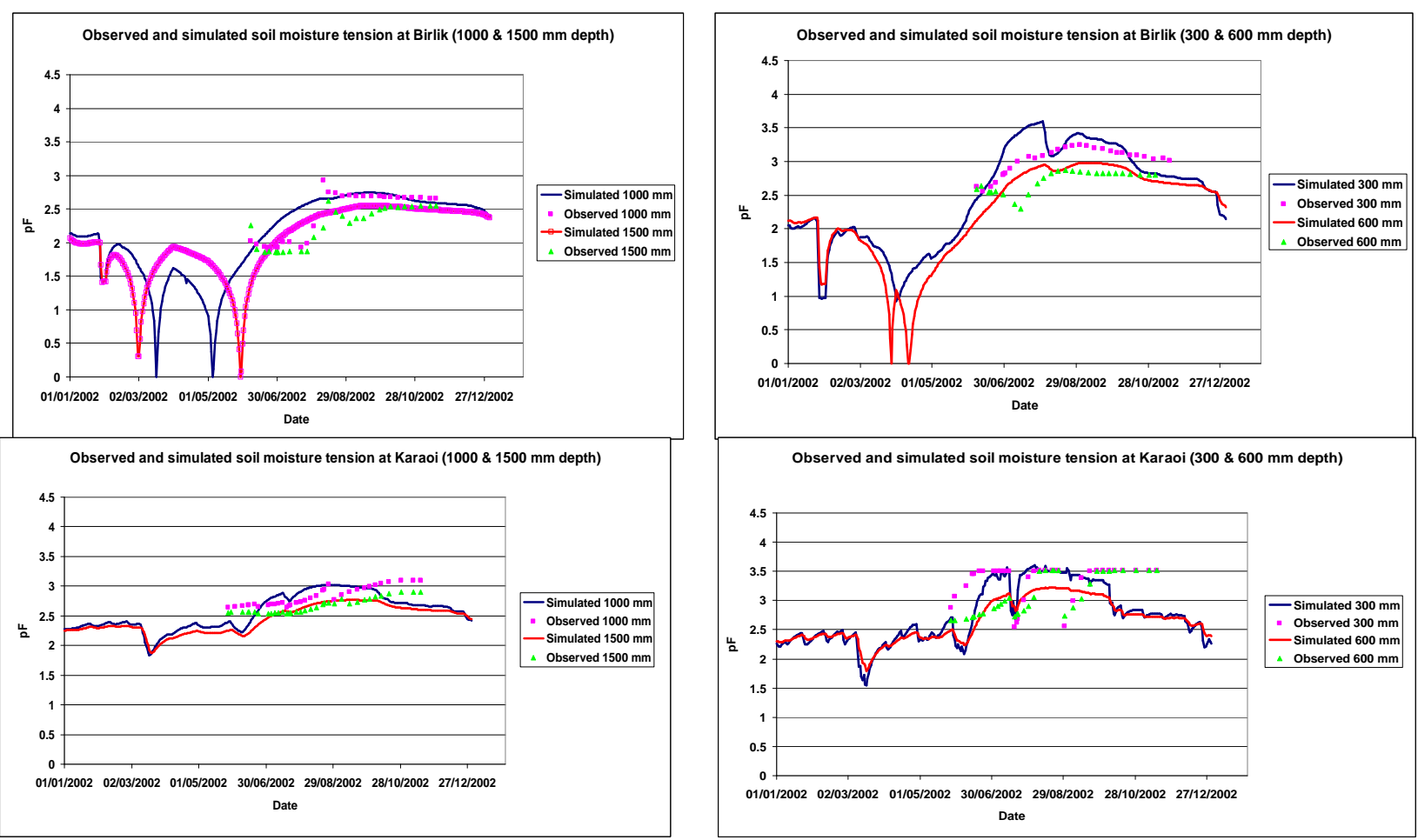

Observed and simulated soil moisture tension at Karaoi ( $300 \& 600 \mathrm{~mm}$ depth)
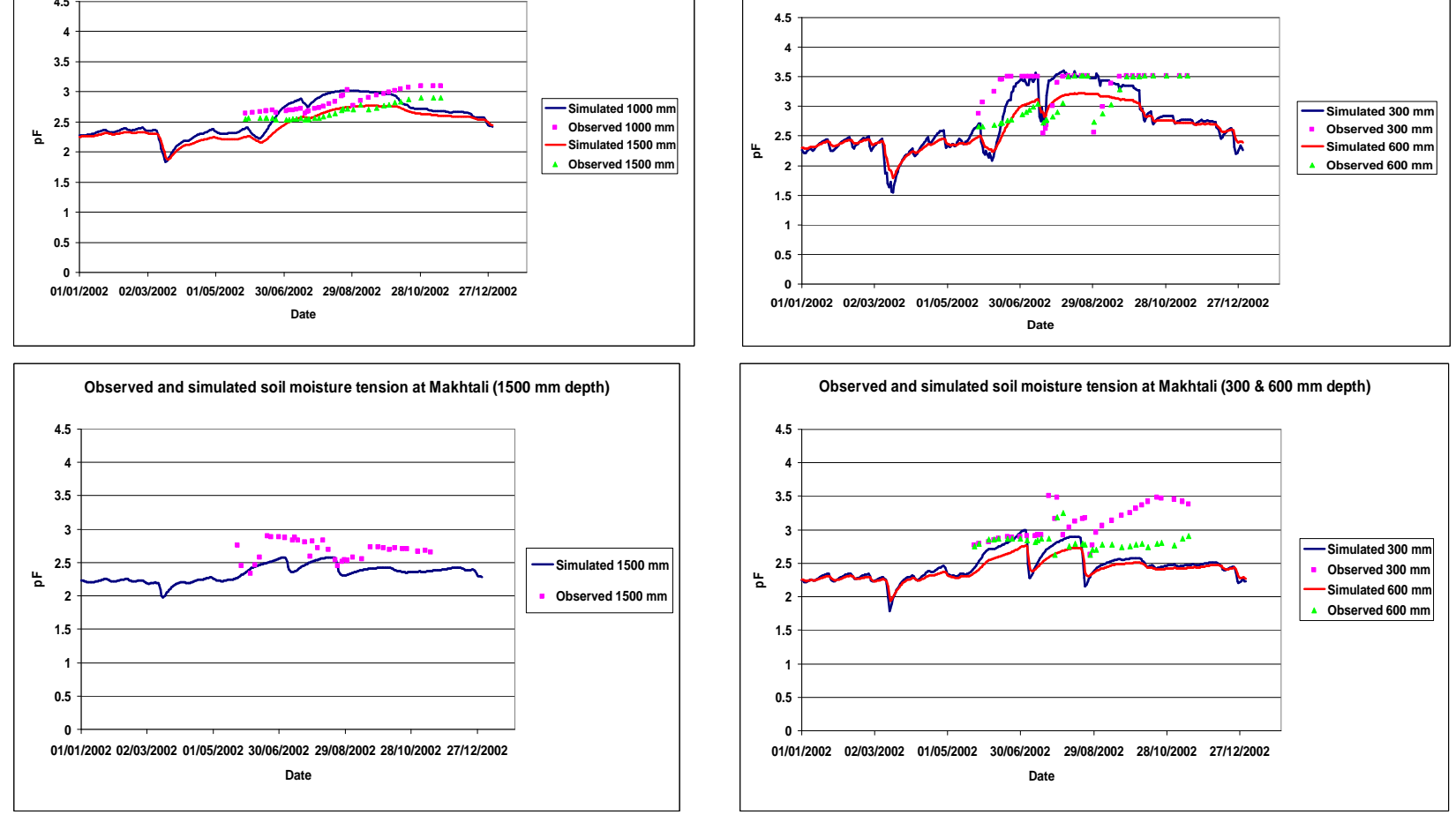

Figure 5. Soil moisture tension at different sites
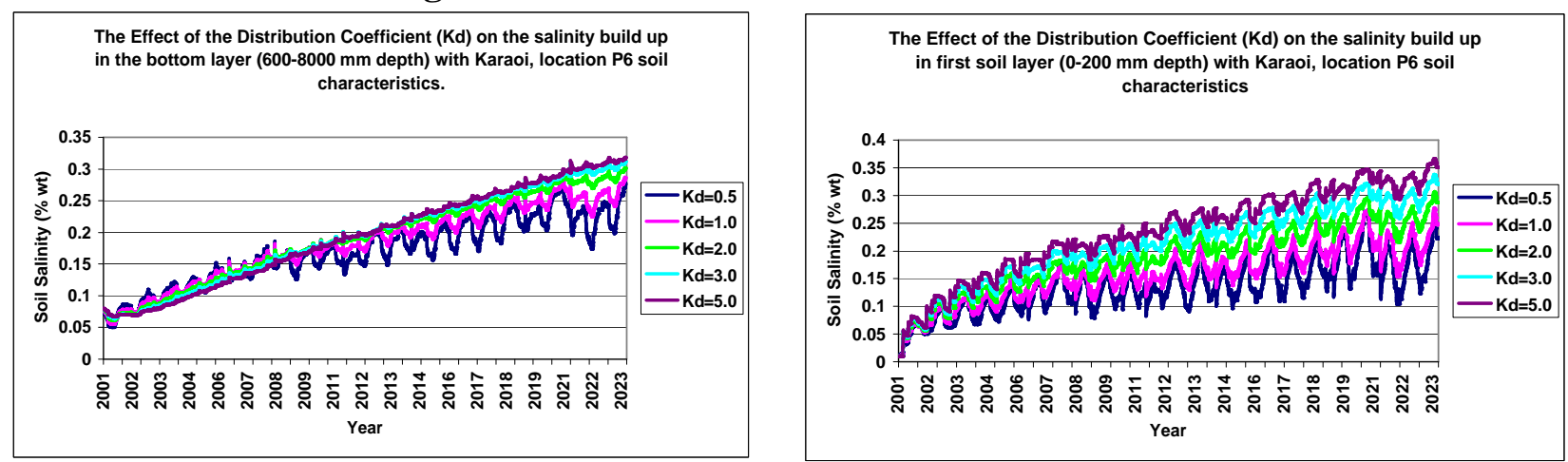

Figure 6. Salinity Build up at Karaoi, location P6 
With high values of $K_{d}$ lower crop yields are simulated than with low values of $K_{d}$, because a higher mass of solutes remains in the soil root zone. According to these results, it is very important to determine a value of $K_{d}$ that permits reasonable salinity simulation, and reflects the observed salinity level in the project area accurately. The difficulty is that, only a few soil salinity observations are available and are insufficient to permit confident definition of $K_{d}$. A $K_{d}$ value of 1.0 was chosen as being a representative value for the whole area, except for Birlik, where a value of 2.0 has been used.

Establishment of efficient irrigation and drainage practice become easier if the most effective variables or parameters influencing response are identified. Another series of model sensitivity runs were carried out for the period 2001-2025. In these runs the sensitivity of irrigation and drainage management variables such as irrigation water application, irrigation water quality, leaching amount and drainage rate were tested to examine their effect on salinity build up over the simulation period. These variables are considered to be the most important factors for the establishment of efficient irrigation and drainage management practices. Sensitive variables are those that have a significant effect on salinity build up. Variables that are identified as significantly sensitive need to be treated more carefully in the construction of the scenarios required for the establishment of efficient irrigation and drainage water management. The sensitivity analysis was performed by varying each of the above mentioned variables while others were kept constant.

The sensitivity of the irrigation water application was tested in the range of $100-400 \mathrm{~mm}$ in increment of $100 \mathrm{~mm}$ in the rate of $100 \mathrm{~mm}$ each 30 days while leaching amount, irrigation water salinity and annual drainage were kept constant at $300 \mathrm{~mm}, 1000 \mathrm{mg} / \mathrm{l}$ and $200 \mathrm{~mm}$, respectively. Figure 7 shows the salinity build up in the rootzone under different irrigation water applications. It is clear that, irrigation water application has a great influence on simulated salinity. Soil salinity increased by $49 \%$ as irrigation water application increased from 100 to $400 \mathrm{~mm}$. The simulation results show that, with irrigation water salinity of $1000 \mathrm{mg} / \mathrm{l}$, large irrigation application cause more salt accumulation in the rootzone even with $300 \mathrm{~mm}$ leaching. Irrigation water quality also has a significant impact on the salinity build up in the rootzone. The lower the quality of the irrigation water, the higher the salt loads in the rootzone (Figure 7). With large irrigation water applications of low quality, keeping salinity levels in the rootzone under control can only be achieved with adequate drainage rate (Figure 7). In other words, salinity levels in the rootzone cannot be kept constant unless the amount of salts added to the profile through irrigation water equals the amount of salts leached from the profile by drainage.

Under low salinity conditions such as those of Karaoi, location P6, increasing the leaching amount from 100 to $300 \mathrm{~mm}$ has only a small effect on the salinity build up in the rootzone, which remains similar using 100, 200 and $300 \mathrm{~mm}$ of leaching over the simulation period (Figure 7). Soil salinity slightly decreases with increasing leaching. Accordingly, this variable can be ignored under such conditions. Key parameters in this case are irrigation water application and drainage rate.

Simulating salinity build up in the WAVE_MS model requires calibration of the distribution coefficient $K_{d}$, and to do this a high frequency of data on observed salinity are required throughout the calibration period. The fewer the samples the less well constrained is the calibration. Unfortunately, the available soil salinity data for the WRMLIP project are poor in number and quality. Because of this, great difficulty was experienced in trying to produce matches between the simulated and observed data. In the calibration processes it was not possible to reach a reasonable agreement between observed and simulated soil salinity. The restrictions in getting a good model performance in simulating soil salinity are the number and quality of the field data. The soil salinity data collected during fieldwork were very few and had some shortcomings. These shortcomings could be related to sampling errors and heterogeneity.

Figure 8 shows the simulated and observed soil salinity in selected pilot areas. In addition to the graphical presentation, the high variation between observed and simulated soil salinity values is indicated by low values of $R^{2}, E F_{2}$ and relatively high values of $C D$. There are, however, few data points and while clearly the simulation of the order of magnitude of salinity is satisfactory, the data do not permit detection of increasing trends or seasonal variability. In addition, the reason for differences at some locations is thought be related to laboratory error. However, the statistics indices appear better at Karaoi, location P3 than at other sites. 

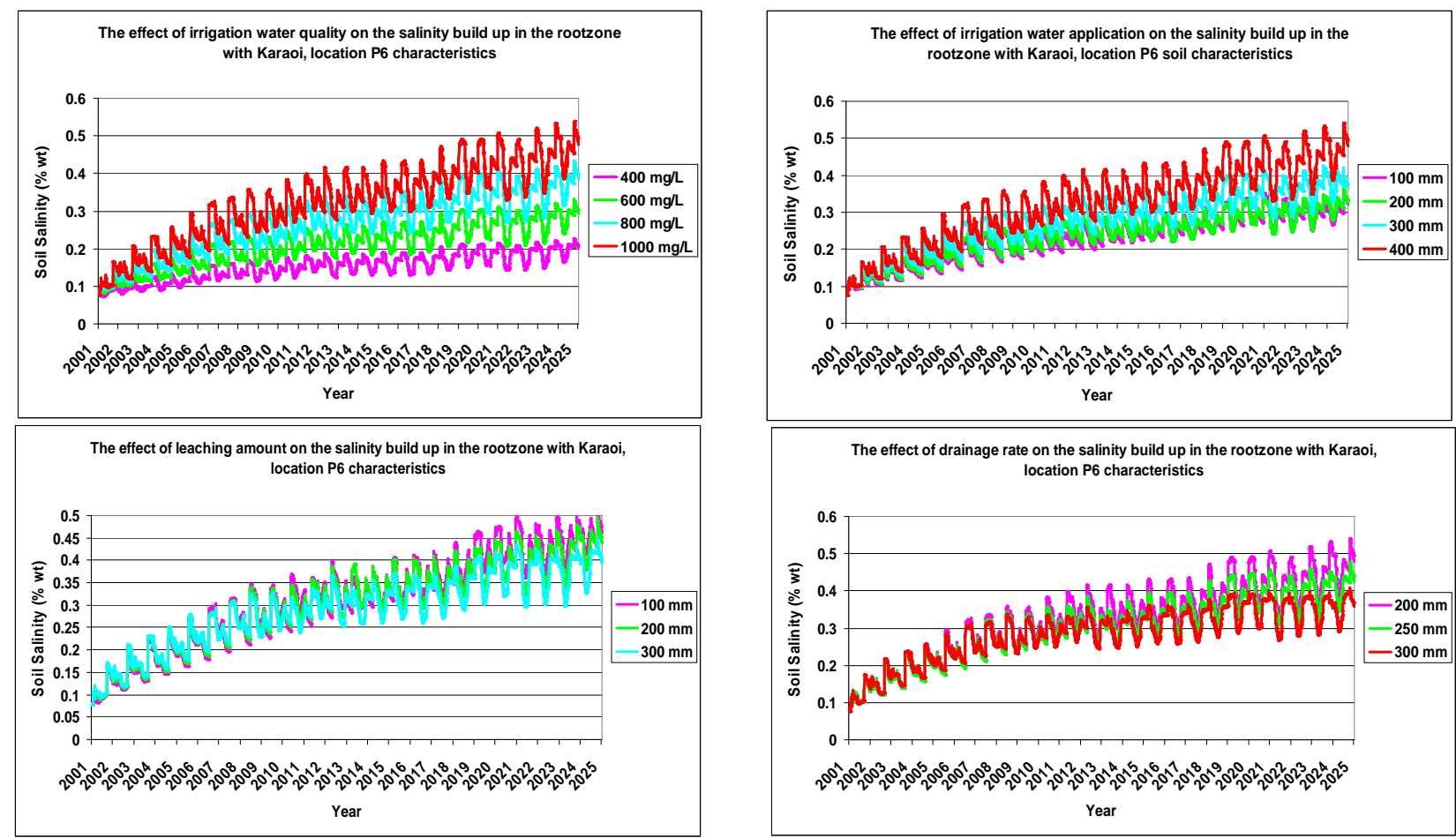

Figure 7. Impact of irrigation water application, irrigation water quality, drainage rate and leaching amount on the salinity build up
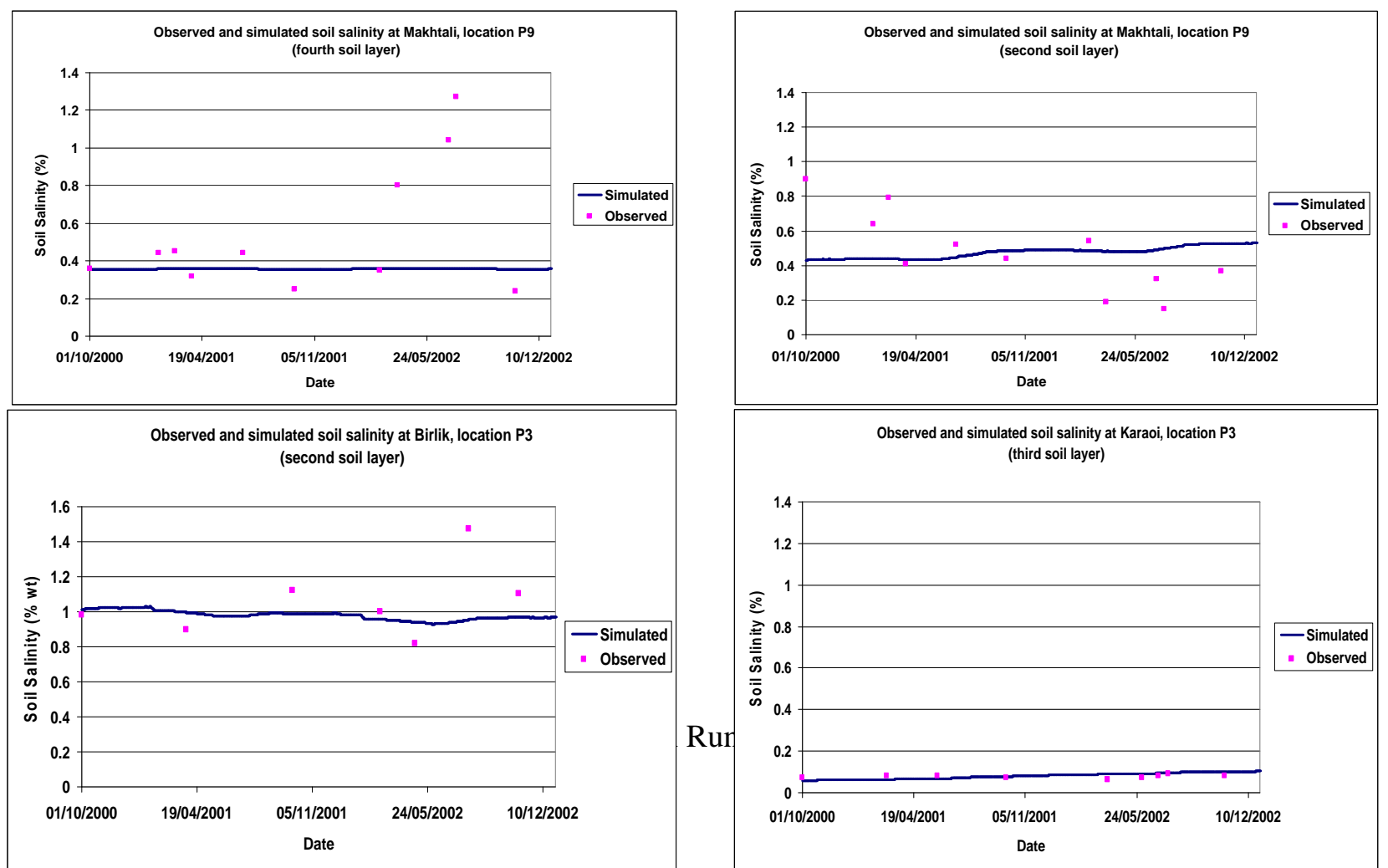

Figure 8. Makhtali site P9 Calibration Run - Soil salinity (200-400 mm depth) 


\section{Evaluation of the current irrigation and drainage management practices}

The modified WAVE model has been applied to evaluate current irrigation and drainage practices in the three pilot areas in the WRMLIP project area. The simulations have been driven by available historic rainfall and potential evapotranspiration data. Only13 years of historic data were available and the historic sequence was simply repeated to provide a 25 year simulation period. This was considered to be sufficiently long to detect long-term salinity impacts.

In the simulation of the current irrigation and drainage practices, the actual irrigation time, amounts applied, and the present level of soil salinity at each location, as recorded in 2002 (Mott MacDonald, 2003a), were used as model inputs. The objective was to assess the effect of the water application, leaching amount and drainage rates on salinity build up, crop transpiration and subsequently on crop yield.

\section{Crop water requirements}

It is clear that since the 1990's, water supplies to the project area have been significantly lower than required for sustainable crop production. Reasonable crop yield cannot be achieved without adequate irrigation. Reductions in cotton yield in the region are attributed to inadequacy of irrigation, in addition to other factors such as soil salinity and waterlogging. Mott MacDonald (2003c) reported that soil water stress is the dominant factor effecting crop yield; the effect of salinity and water logging is significantly lower at the present time at most locations.

In all pilot areas in 2001, the total water applications (both irrigation and rainfall but excluding leaching application) were very low and could meet only $13 \%-17 \%, 20 \%-26 \%$ and $26 \%$ of the total crop water requirements in Birlik, Makhtali and Karaoi areas respectively. Even if the leaching amounts are considered to meet a part of the crop requirements, only

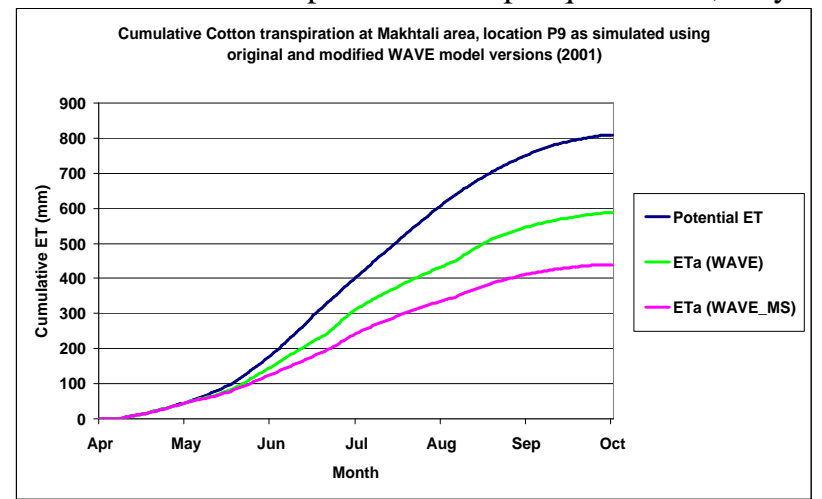

$35 \%-47 \%, 32 \%-37 \%$ and $44 \%$ of the seasonal water requirements would have been met. Under the current conditions, crops in most locations have part of their

water requirements met by root water uptake from the shallow watertable. Simulation results indicate that the amount of water supplied by the upward flux from the shallow watertable during the growing season in 2001 met $10 \%-35 \%$ of the total crop water requirements, depending on location.

Figure 9 shows cumulative potential and simulated actual crop evapotranspiration at location P3 in the Karaoi pilot area in 2001. The simulated actual crop evapotranspiration during the growing season from mid-April to mid-October was about $473 \mathrm{~mm}$ compared with $809 \mathrm{~mm}$ potential evapotranspiration. About $35 \%$ of the total crop water requirement $(60 \%$ of the actual water use) at this location was met through the upward flux from the water table. Only $67 \%$ of the potential crop yield was achieved. In terms of individual growth stages, there was a reduction in the crop water requirements by $7 \%, 26 \%, 50 \%$ and $51 \%$ for vegetative, flowering, yield formation and ripening stages respectively. This resulted in yield reductions of $2 \%, 12 \%, 25 \%$ and $33 \%$ for the same growth stages respectively. As the soil salinity in Karaoi area is still under the threshold value for salinity stress, crop transpiration simulated using original and WAVE_MS model versions was the same and the reduction in crop transpiration and yield was due to only the effect of soil water stress.

Cotton plants in the Makhtali and Birlik areas are under the effects of both soil water stress and salinity stress. As a result, crop transpiration is lower than in Karaoi. For example, at location P9 in the Makhtali area, the simulated actual crop transpiration was about $440 \mathrm{~mm}$; meeting only $54 \%$ of the total crop water requirements (Figure 9). $234 \mathrm{~mm}$ (53\%) of the actual crop water use was provided by upward flux from the

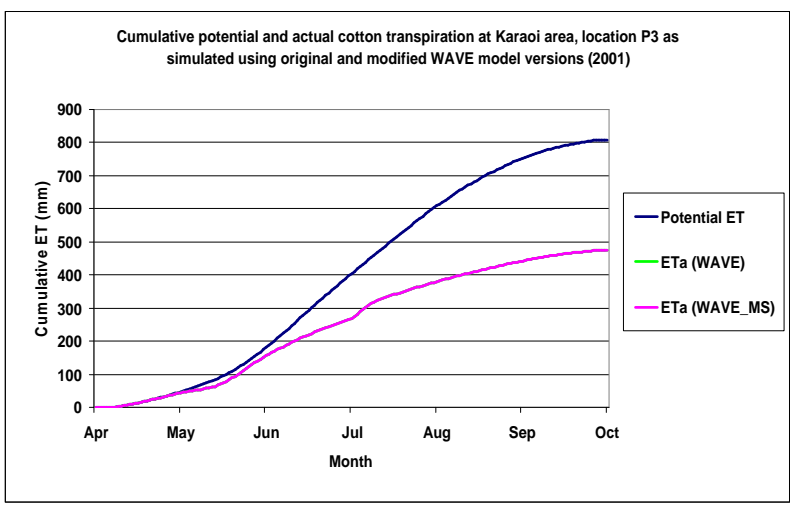

Figure 9. Simulated potential and actual cotton transpiration at Karaoi and Makhtali areas 
water table. The simulated crop yield was $54 \%$ of potential. As soil salinity in the Birlik and Makhtali areas is above the salt-tolerance threshold value, crop transpiration simulated using original WAVE model was higher than that simulated using the WAVE_MS model because the original version doesn't take into account the effect of salinity stress on transpiration.

\section{Soil Salinity}

According to the salinity data presented in the data collection reports(Mott MacDonald, 2003a), soil salinity in the Birlik and Makhtali areas is above the salt-tolerance threshold value of $7.7 \mathrm{dS} / \mathrm{m}$ for cotton $(0.47 \%$ of dry soil weight). However, it is below threshold in the Karaoi area. The WAVE_MS model has been used to predict the soil salinity over a 25-year (notionally 2001 - 2025) simulation period. Although, water applications have been low in recent years, adequate supply would have led to a worse salinity problem than now exists in some locations in view of the poor drainage that has existed. The simulation results indicate that, rootzone salinity at Makhtali location P9 would rise by about $51 \%$ by the year 2025 (Figure 10) if recent irrigation and drainage practices were to continue. This would result in crop yield reduction due to salinity stress of about $44 \%$, in addition to the

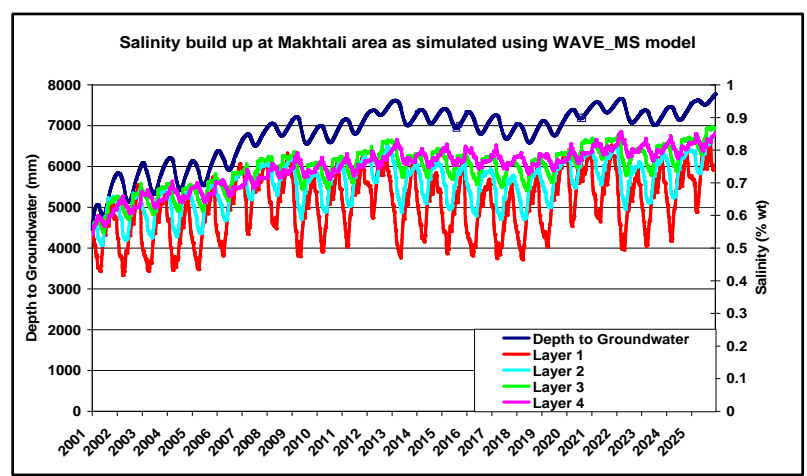

Figure 10. Salinity build up at Makhtali area, location P9
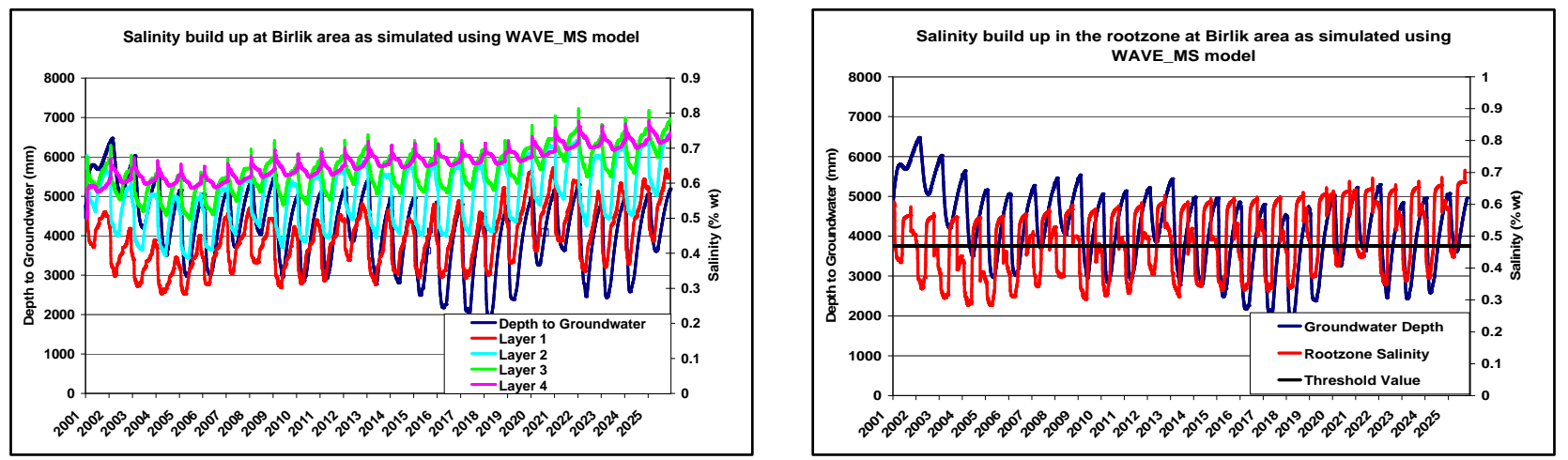

Figure 11. Salinity build up at Birlik area, location P3

reduction due to water stress. Figure 10 shows that soil salinity in other soil layers follows the same trend as salinity in the rootzone. The rate of salt accumulation in all layers is relatively slow. Although there was no drainage, the water table in the area falls from $4.5 \mathrm{~m}$ to be lower than $7.5 m$ over most of the simulation period as a result of the water uptake by the plant roots.

In the Birlik area, a solute distribution constant $\left(K_{d}\right)$ value of 2.0 was used in the simulation, which is higher than the $K_{d}$ values, used for other locations. A $K_{d}$ value of 2.0 means that the leaching process is less effective than if the value was 1.0. However, root zone salinity in Birlik increased from $0.6 \%$ to only $0.71 \%$ over the simulation period to reduce the yield by about $33 \%$ in addition to the reduction due to water stress. Figure 11 shows salinity build up at location P3 in the Birlik area. As a result of the higher water table in this area, salinity build up rate in the bottom soil layers is high. However, salinity build up in other layers is relatively slow. This is as a result of the continuous leaching of salts each year and the fact that salt loadings are relatively low because of inadequate irrigation. The threshold value given in the following figures is the salinity at which crop yield begins to be affected.

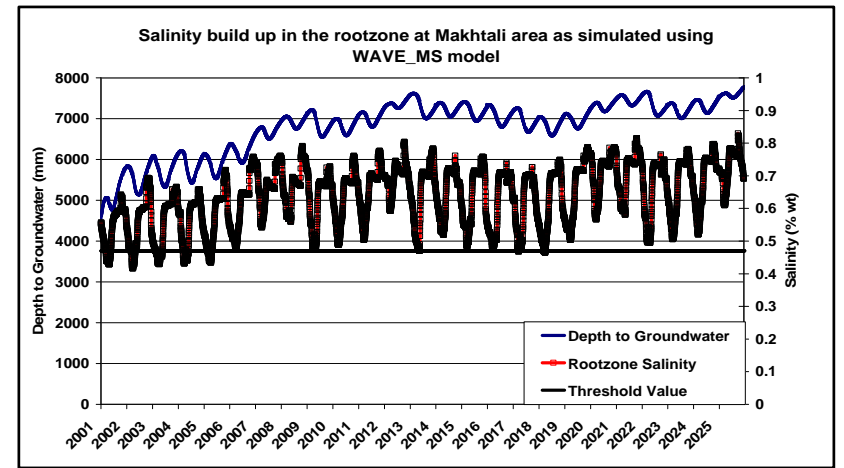

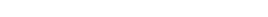


In the Karaoi area, soil salinity remained under the critical value over the entire simulation period. The rate of salt accumulation is similar in all soil layers. The amount of salts added to the soil profile is similar to that observed at Makhtali. Over the 25 year simulation, 3.7 $\mathrm{Kg} / \mathrm{m}^{2}$ of salt is added to the soil profile compared with $4.0 \mathrm{Kg} / \mathrm{m}^{2}$ and $3.0 \mathrm{Kg} / \mathrm{m}^{2}$ added to the soil profile at Makhtali and Birlik areas respectively. Figure 12 shows salinity build up in the root zone at Karaoi location P3. At Karaoi soil salinity started from a lower base, but there could eventually be a salinity problem.

As there was no salinity or waterlogging effects in the Karaoi area, the reduction in crop yield over the simulation period is related to the water stress only. The fluctuations in the depth to groundwater from one year to another are related to the variation in the seasonal rainfall and crop transpiration between years.

\section{Crop yield}

Long-term historical data on crop yield are not available to permit evaluation of the impact of the current irrigation and drainage management practices.

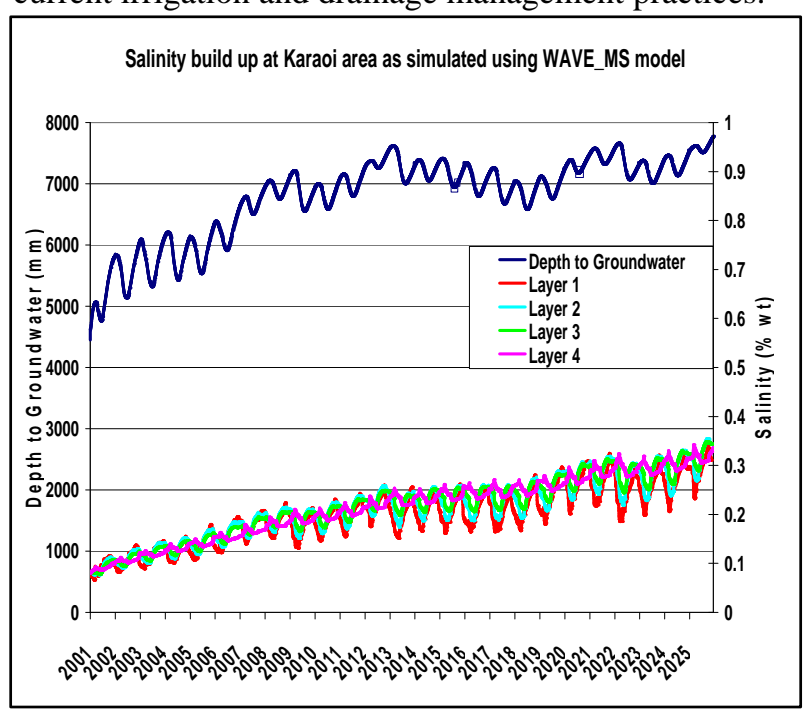

The WAVE_MS model has been used to assess the combined effect of water supply, soil salinity, and waterlogging on crop yield.

Two years (2001 and 2002) of observed cotton yields in the pilot areas expressed as a percent of potential maximum yield (taken as 3.9 tonne/ha) were compared with simulated yields using the WAVE_MS model. Results are shown in Table 13. There is an overestimation of the cotton yield by $14 \%$ at Makhtali and Karaoi in 2001. However, a good match with the observed yields was obtained at Birlik in both years. The model underestimates cotton yield by about $21 \%$ and $9 \%$ in Makhtali and Karaoi in 2002, respectively. The overestimation of cotton yield in Makhtali and Karaoi in 2001 can be related to factors such as plant diseases and nutrients deficiency, which caused yield reduction in addition to the effects of water stress and salinity. The model has only considered water and salinity stress. In 2002 the yield simulation at Birlik and Karaoi was reasonably good, but the very high yield reported for Makhtali was not reproduced. It is thought likely that there has been some anomaly in this

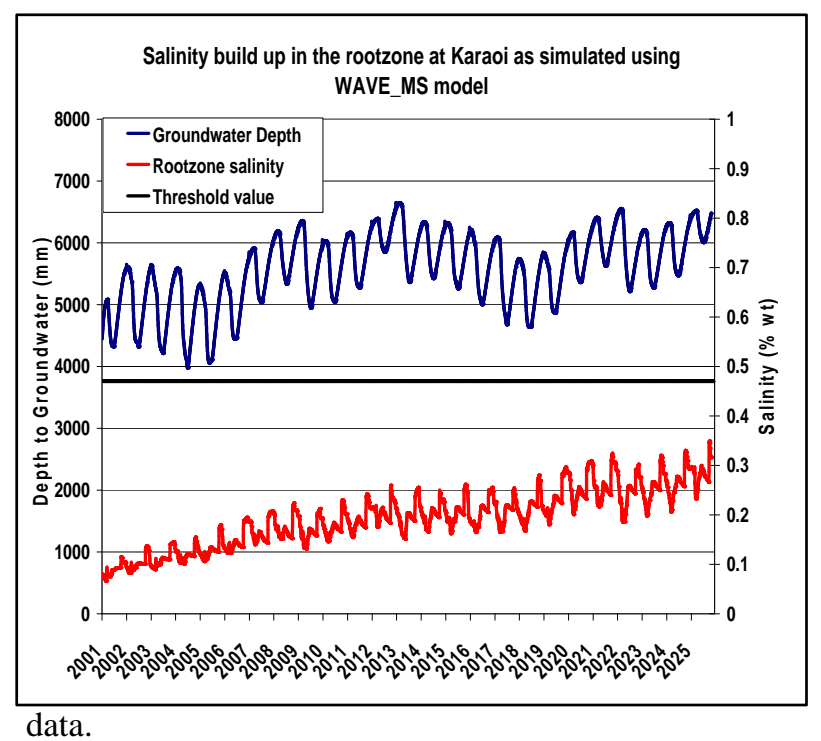

Figure 12. Salinity build up at Karaoi area, location P3

Table 13. Average observed and simulated cotton Yield in pilot areas, (\%)

\begin{tabular}{lccc}
\hline \multirow{2}{*}{ Pilot Area } & \multicolumn{3}{c}{ Average Yield (\%) } \\
\cline { 2 - 4 } & Observed & Simulated \\
\hline & & $\mathbf{2 0 0 1}$ & 54 \\
\hline Makhtali & 40 & & 46 \\
Birlik & 48 & & 67 \\
Karaoi & 53 & $\mathbf{2 0 0 2}$ & \\
\hline
\end{tabular}




\begin{tabular}{lll}
\hline Makhtali & 75 & 54 \\
Birlik & 53 & 51 \\
Karaoi & 78 & 69 \\
\hline
\end{tabular}
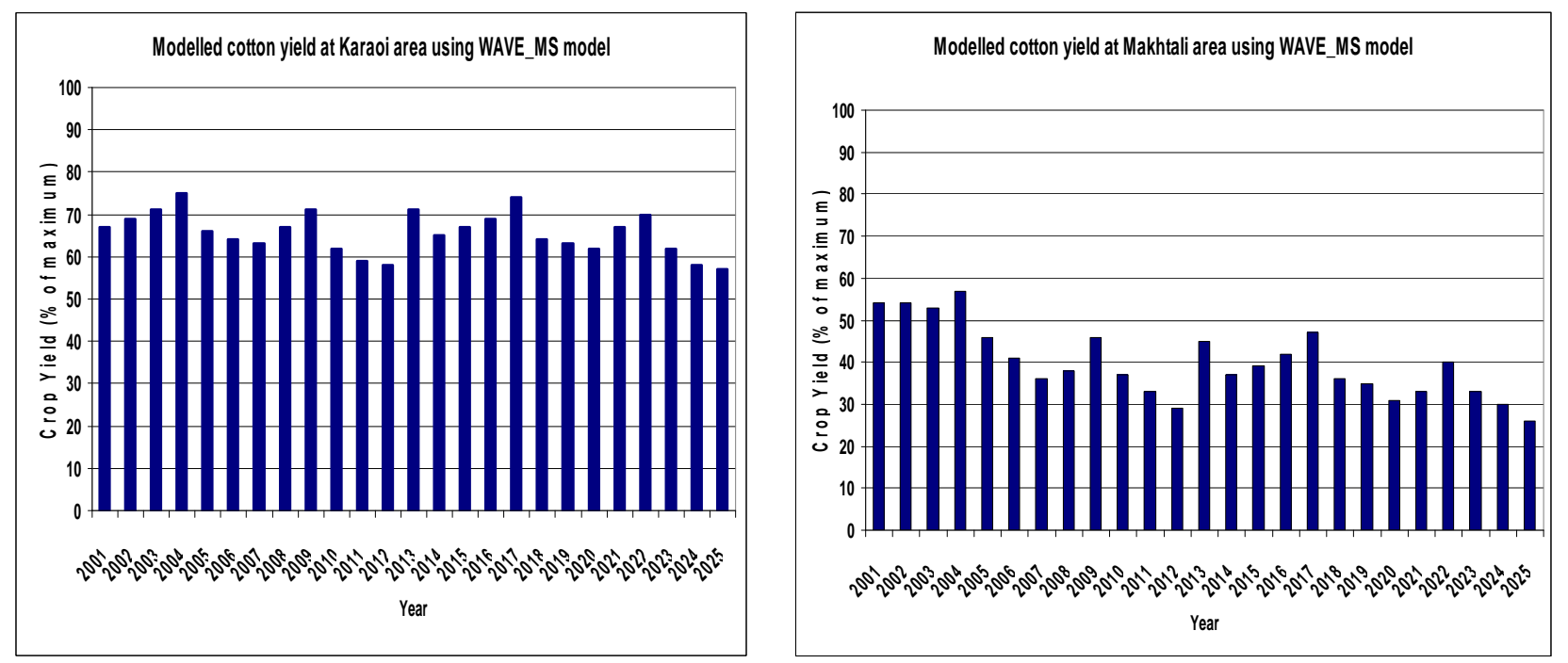

\section{Figure 13. Cotton yield at Karaoi and Makhtali areas as simulated using modified WAVE_MS model}

Cotton yield was simulated using the WAVE_MS model for a period of 25 years (2001-2025) to investigate long-term water stress and salinity effects on cotton yield, assuming that recent irrigation and drainage practices continued. In the Makhtali and Birlik areas, cotton yield is under the effect of both soil salinity and soil water stress. As a result, the average reduction in crop yield was about $50 \%$ in the year 2002 in both areas. Average yield in these two areas decreased sharply from the initial values of about $54 \%$ and $45 \%$ in the first year of simulation. Figure 13 shows that by the year 2025, with continuation of recent irrigation and drainage practices, $70 \%$ of the potential crop yield would be lost from the Makhtali area. Increasing soil salinity is the cause of continued decline in yields.

Since soil salinity in the Karaoi area remains below the threshold value for salinity stress throughout the simulation period, reduction in cotton yield is attributed to soil water stress only. The reduction in yield would remain around $30 \%-40 \%$ until the salinity exceeds the threshold value (Figure 13). At that time the reduction in yield will increase as the salinity increases. The combined effect of water stress and salinity is more harmful to crop yield than the individual effect of water stress. The slight fluctuations in crop yield from one year to another are related to variations in the seasonal rainfall between years.

\section{CONCLUSIONS}

The modified model was set-up and calibrated using field data collected by Mott MacDonald from three pilot areas in South Kazakhstan. In terms of soil moisture

content and soil salinity, the calibration results have been satisfactory. However, soil salinity and soil moisture tension calibration was restricted by the number and quality of the data from the pilot area data collection programme. Soil salinity and soil moisture tension calibration need to be improved when more data of good quality become available. The results show poor performance in simulating soil moisture tension and soil salinity. Model calibration is limited by the number and quality of soil moisture tension and salinity data, more frequent and careful monitoring of these field data are required. The model would require recalibration when more soil salinity data of good quality become available. An on-going field programme would permit more reliable calibration and validity of the model. The more data of good quality that can be collected the better will be model performance.

Generally, the reasonable agreement between observed and simulated soil moisture gives confidence that the WAVE_MS model can be used to predict long term water balance as well as investigating long-term salinity build up in the root zone and the effect of moisture and salinity stress on crop yield. 
From the WAVE_MS simulation outputs, it is clear that the irrigation supply to farmers has been inadequate in recent years. Irrigation applications for cotton have been significantly less than its requirements and there has been water stress during most of the growth period. Were current practices to continue there would be a continued decline in crop yields as a result of water stress and an ever increasing soil salinity. 



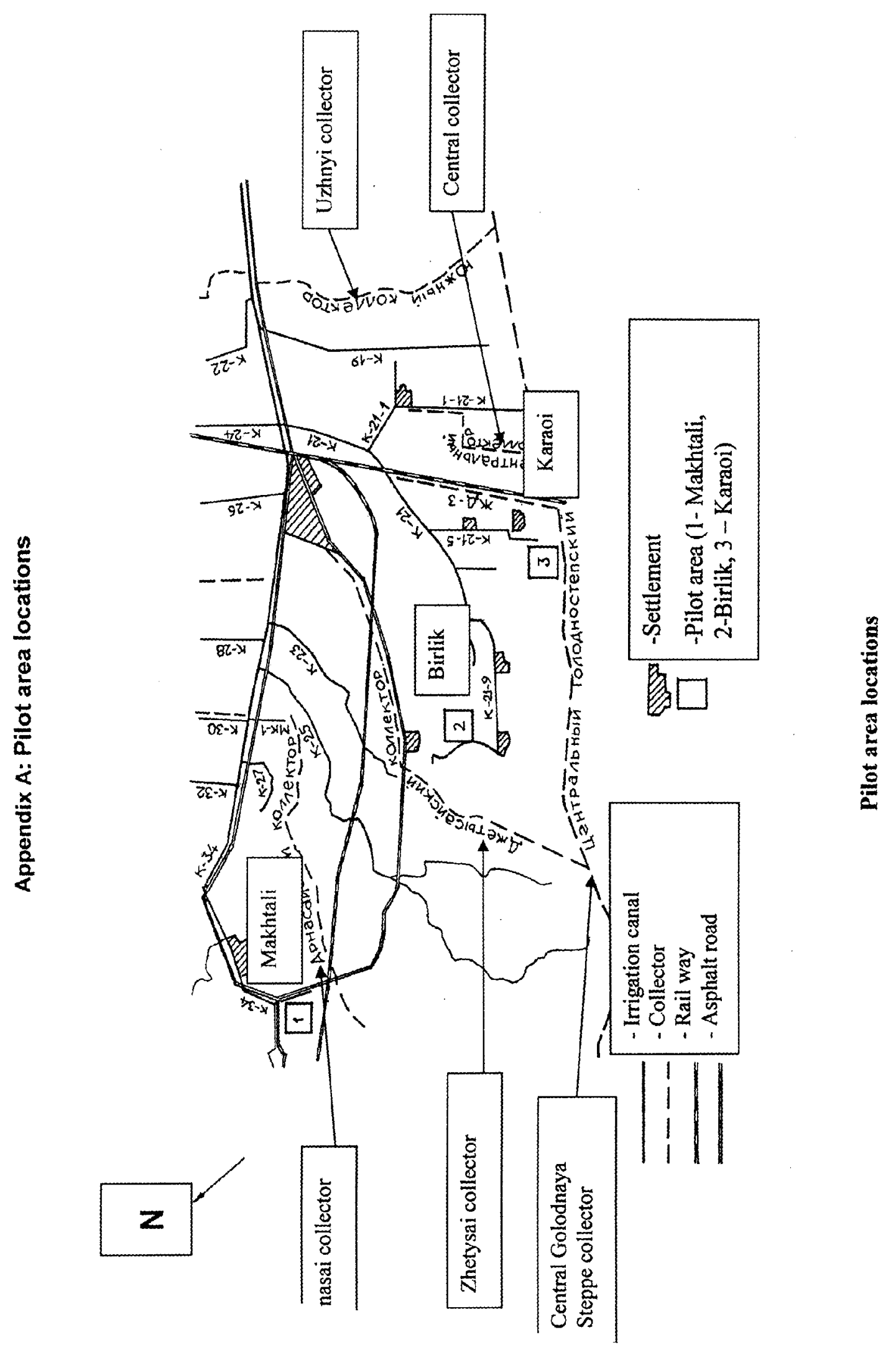




\section{REFERENCES}

ADB (Asian Development Bank). (1997). Report and recommendations of the President to the Board of Directors on Proposal Loans and Technical Assistance Grant to the Republic of Kazakhstan for the Water Resources Management and Land Improvement Project. Manila, Philippines

Allen, R. L., Raes, D., and Smith, M. (1998). "Crop Evapotranspiration: Guidelines for computing crop water requirements." Irrigation and Drainage Paper No. 56, FAO, Rome, Italy.

Doorenbos, J., and Kassam, A. (1979). "Yield response to water" FAO Irrigation and Drainage Paper No. 33, Food and Agriculture Organisation, United Nations, Rome.

Droogers, P., Bastiaanssen, W. G. M., Beyazgul, M., Kayam, Y., Kite, G. W., and Murray-Rust, H. (2000). "Distributed agro-hydrological modelling of an irrigation system in western Turkey." Agric. Water Management, 43: 183-202.

Droogers, P., and Kite, G. (2001). "Simulation modelling at different scales to evaluate the productivity of water." Phys. Chem. Earth, 26: 877-880.

Droogers, P., and Torabi, M. (2002). " Field scale scenarios for water and salinity management by simulation modelling." Research Report 12. Iranian Agricultural Engineering Research Institute (IAERI), Karaj, Iran, International Water Management Institute (IWMI), Colombo, Sri Lanka.

Feddes, R. A., Kowalik, P. J., and Zaradny, H. (1978). "Simulation of field water use and crop yield." Simulation Monographs. Pudoc, Wageningen.

Fernandez, J. E., Slawinski, C., Moreno, F., Walczak, R. T., and Vanclooster, N. (2002). "Simulation the fate of water in a soil-crop system of a semi-arid Mediterranean area with the WAVE 2.1 and the EURO-ACCESS-II models." Agric. Water Management, 1738:1-17.

Gupta V. K., and Sorooshian, S. (1998). "Toward improved calibration of hydrologic models: Multiple and noncommensurable measures of information." Water Resour. Res., 34(4): 751-763.

Joshi, M. B., Murthy, J. S. R., and Shah M. M. (1995). "CROSOWAT: A decision tool for irrigation schedule" Agric. Water Management, 27:203-223.

Kite, G., and Droogers, P. (2000a). “ Integrated basin modelling." Research Report 43. Colombo, Sri Lanka: International Water Management Institute (IWMI).

Legates, D. R., and McCabe, G. J. (1999). "Evaluating the use of "goodness-of-fit" measures in hydrologic and hydroclimatic model validation." Water Resour. Res., 35(1): 233-241.

Loague, K., and Green, R. E. (1991). "Statistical and graphical methods for evaluating solute transport models: Overview and applications." Journal of contaminant Hydrology, 7:51-73.
Motovilov, Yu. G., Gottschalk, L., England, K., and Rodhe, A. (1999). "Validation of a distributed hydrological model against spatial observations." Agric. Forest. Meteorol, 98-99:257-277.

Mott MacDonald. (1999). Water Resources Management and Land Improvement Project (WRMLIP), Inception Report, Govt. of Kazakhstan.

Mott MacDonald. (2000a). Water Resources and Land Improvement Project (WRMLIP), Working Paper No. 11a: Review of Drainage Needs. Govt. of Kazakhstan.

Mott MacDonald. (2000b). Water Resources and Land Improvement Project (WRMLIP), Working Paper No. $11 b$ : Status Report, Govt. of Kazakhstan.

Mott MacDonald. (2002). Water Resources and Land Improvement Project (WRMLIP), Working Paper No. 22: Preliminary Evaluation of Pilot Farm Data and WAVE Modelling. Govt. of Kazakhstan.

Mott MacDonald. (2003a). Water Resources and Land Improvement Project (WRMLIP), Scientific Report on Organisation Works and Field Investigation on Pilot Areas (2000-2002). Govt. of Kazakhstan.

Mott MacDonald. (2003b). Water Resources and Land Improvement Project (WRMLIP), Working Paper No. 27: Soil Monitoring Programme Results. Govt. of Kazakhstan.

Mott MacDonald. (2003c). Water Resources and Land Improvement Project (WRMLIP), Working Paper No. 29: WAVE Set-up, Calibration and Prediction. Govt. of Kazakhstan.

Mott MacDonald. (2003d). Water Resources and Land Improvement Project (WRMLIP), WRMLLLIP_WAVE model users manual, Govt. of Kazakhstan.

Mott MacDonald. (2004). Water Resources and Land Improvement Project (WRMLIP), Working Paper No. 30: Modelling Synthesis. Govt. of Kazakhstan.

Querner, E. P., Morabito, J. A., Manzanera, M., Pazos, J.A., Ciancaglini, N. C., and Menenti, M. (1997). "The use of hydrological models in the irrigation areas of Mendoza, Argentina." Agric. Water Management, 35: 11-28.

Qureshi, S. A., Madramootoo, C. A., and Dodds, G. T. (2002). "Evaluation of irrigation schemes for sugarcane in Sindh, Pakistan, using SWAP93." Agric. Water Management, 54: 37-48.

Rao, N. H., Sarma, P. B., and Chander, S., 1988. "A simple dated water production function for use in irrigated agriculture.” Agric. Water Management. 13:25-32.

Saleh, M. A. (2006). "Modelling Irrigation Water Management under Water Shortage and Salinity Conditions. " $\mathrm{PhD}$ thesis, Department of Civil and Environmental Engineering, Edinburgh University, Edinburgh, UK.

Simunek, J., Suarez, D. L., and Sejna, M. (1996). "The UNSATCHEM Software package for simulating dimensional variably saturated water flow, heat transport, carbon dioxide production and transport, and solute transport with major ion equilibrium and kinetic 
chemistry." Version 2.0. Research Report No. 141, USDA, ARS, U.S. Salinity Laboratory, Riverside, California

Simunek, J., Huang, K., and van Genuchten, M. Th. (1999). "The HYDRUS-2D software package for simulating the two-dimensional movement of water, heat and multiple solutes in variably saturated media." Version 2.0, IGWMC-TPS-53, International Ground Water Modelling Centre, Colorado School of Mines, Golden, Colorado.

Smets, S. M. P., Kuper, M. Van Dam, J. C., and Feddes, R. A. (1997). "Salinisation and Crop transpiration of irrigated fields in Pakistan's Punjab." Agric. Water Management, 35:43-60.

Vanclooster, M., Viaene, P., Diels., J., and Christiaens K. (1994). "WAVE a mathematical model for simulating water and agrochemicals in the soil and vadose environment." Institute for Land and Water Management, Katholieke University of Leuven, Leuven, Belgium.

Van Dam, J. C., Huygen, J., Wesseling, J. G., Feddes, R. A., Kabat, P., van Waslum, P. E. V., Groenendjik, P., and Van Diepen, C. A. (1997). "Theory of SWAP version 2.0: Simulation of water flow and plant growth in the Soil-Water-Atmosphere-Plant environment." Technical Document 45, Wageningen Agricultural University, Wageningen, The Netherlands.
Van Dam, J. C. (2000). "Field-scale water flow and solute transport: SWAP model concepts, parameter estimation and case studies." Ph.D. thesis, Wageningen University, Wageningen, The Netherlands.

Van Genuchten, M. Th. (1980). "A close-form equation for predicting the hydraulic conductivity of soil." Soil Sci. Soc. Am. J., 44:892-898.

Vazquez, R. F., and Feyen, J. (2003). "Effect of potential evapotranspiration estimates on effective parameters and performance of the MIKE SHE-code applied to a medium-size catchment." Journal of Hydrology, 270: 309-327.

Wang, H., Zhang, L., Dawes W. R., and Liu, C. (2001). "Improving water use efficiency of irrigated crops in the North China plain-measurement and modelling." Agric. Water Management, 48: 151-167.

WUFMAS. (1999). "Water Use and Farm Management Survey (WUFMAS)." Annual Report. Tacis Service DG 1A, European Commission, Brussels.

Xevi, E., Gilley, J., Feyen, J. (1996). "Comparative study of two crop yield simulation models." Agric. Water Management, 30:155-173.

Zhang, L., and Dawes, W.R. (1998). "WAVES an integrated energy and water balance model." Technical Report No. 31/98, CSIRO Land and Water, Canberra, Australia. 


\section{نمذجة رياضية لإدارة مياه الري تحت ظروف نقص المياه والملوحة العالية:

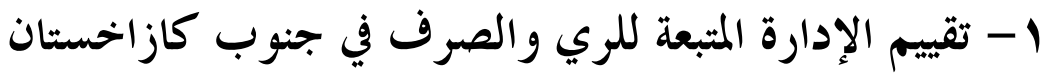

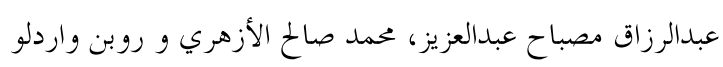

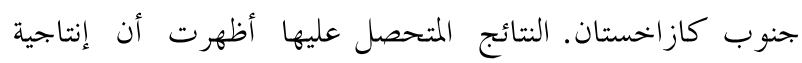

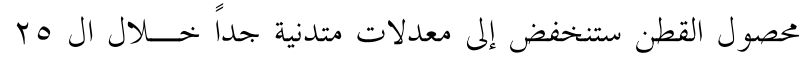

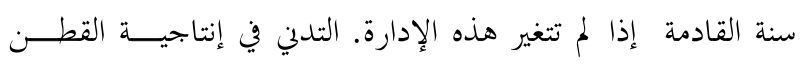

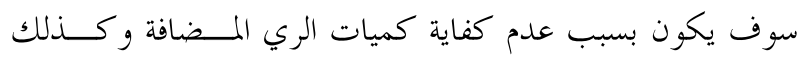

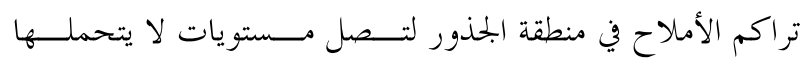

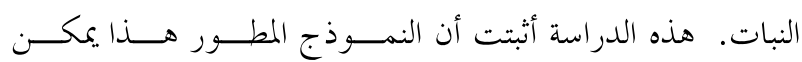

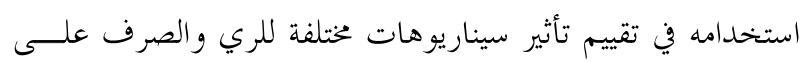

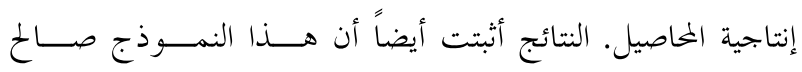

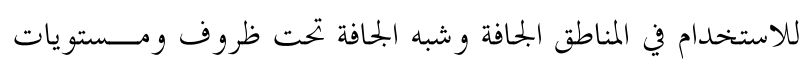
مختلفة نقص المياه والملوحة.
إن النموذج الرياضي WAVE قد تم تطويره ليتضمن تــأثير الملوحة العالية على البخر - نتح وتم استخدامه لمحاكاة حركة كرة المـــاء

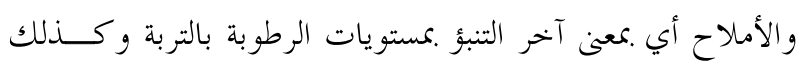

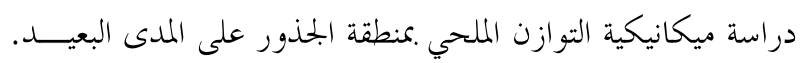

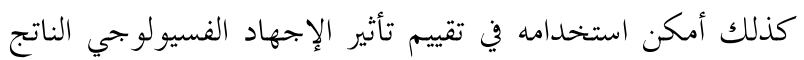

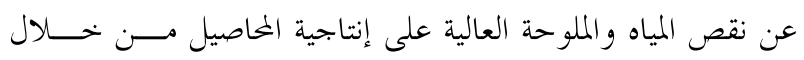

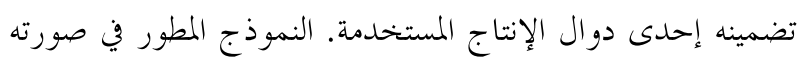

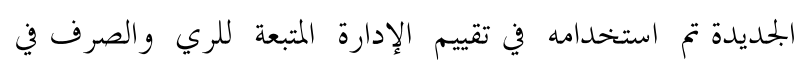

